NBER WORKING PAPER SERIES

THE BASIC ANALYTICS

OF MORAL HAZARD

\author{
Richard J. Arnott \\ Joseph E. Stiglitz
}

Working Paper No. 2484
NATIONAL BUREAU OF ECONOMIC RESEARCH 1050 Massachusetts Avenue Cambridge, MA 02138 January 1988

We would like to thank Seppo Honkapohja and two anonymous referees for useful comments, and the National Science Foundation, the 01 in Foundation, and the Social Sciences and Humanities Research Council of Canada for financial support. The research reported here is part of the NBER's research program in Taxation. Any opinions expressed are those of the authors and not those of the National Bureau of Economic Research. 
NBER Working Paper \#2484

January 1988

The Basic Analytics of Moral Hazard

\begin{abstract}
This paper develops the basic analytics of moral hazard, for the two-artcome case where either a fixed damage accident occurs or it does not. The analysis focuses on the relationship between the insurance premium paid and the insurance benefits received in the event of an accident, and is conducted in benefit-premium space. The central message of the paper is that even when the underlying functions, the expected utility function and the function relating the accident probability to accident-prevention effort, are extremely well-behaved, the indifference curves and feasibility set (the set of insurance contracts which at least break even) are not--indifference curves need not be convex and feasibility sets never are; price-and incomeconsumption lines may be discontinuous; and effort is not in general a monotonic or continuous function of the parameters of the insurance policies provided.

Part I of this paper establishes these results, while Part II discusses same of their implications. The bad behavior of indifference curves and the feasibility set profoundly affects the nature and existence of competitive equilibrium. We illustrate this, though we do not provide a thorough analysis. We also show that our canonical model of an insurance market with moral hazard can be reinterpreted to provide a model of loans with bankruptcy, or of work incentives.
\end{abstract}

Note: $\ddot{a}=\partial, \ddot{y}=\gamma, \varepsilon=\lambda$

Richard J. Arnott

Department of Economics

Queen's University

Kingston, Ontario K7L 3N6

CANADA
Joseph E. Stiglitz

Department of Economics

Princeton University

Princeton, NJ 08544 


\section{The Basic Analytics of Moral Hazard}

In the standard (Arrow-Debreu) campetitive treatment of risk, the states of nature, which ocour with exogenous probabilities, are abservable. Insurance contingent on the realized state entails lumpsum transfers across states and therefore has no incentive or substitution effects.

Moral hazard arises when neither the states of nature nor individuals' actions are observable to an insurer. 1 What is observable is whether a particular accident has occurred. Under these conditions, there is no mechanism by which the insurer can induce the insured to reveal either the state of nature or his level of precaution truthfully. Thus, the insured-against events are accidents of varying degrees of severity, conditional on neither the state of nature nor the insured's actions. The provision of insurance against such events will generally affect the individual's incentives to take precautions ${ }^{2}$ i.e., have substitution effects. There is therefore a tradeoff between incentives and risk-bearing. This is the moral hazard problem.

Moral hazard is pervasive in the economy. It occurs whenever risk is present, individuals are risk-averse, and "effort" is costly to monitor. And it arises not only in insurance markets, but also when

$1_{\text {This is the extreme form of moral hazard. Moral hazard problems }}$ arise, though they are diluted, when the states of nature and/or individuals' actions are imperfectly observable (observable with noise).

2 The provision of insurance therefore affects the probabilities of the events. For this reason, we define moral hazard to arise when the provision of insurance affects the probabilities of the insured-against events. 
insurance is provided by govermments, through social institutions, or in principal-agent contracts.

This paper develops the basic analytics of moral hazard. The analysis focuses on the relationship between the insurance premium paid and the insurance benefits received in the event of an accident. We derive the properties of the indifference curves and of the feasibility set, the set of insurance contracts which at least break even. The central message of the paper is that even when the underlying functions, the expected utility function and the relationship between effort and the accident probability, are extremely well-behaved, the indifference curves and feasibility sets are not-indifference curves need not be convex and feasibility sets never are; price- and incomeconsumption lines may be discontinuous; and effort is not in general a monotonic or continuous function of the parameters of the insurance policies provided or of the prices of goods.

Part I of this paper establishes these results, while Part II discusses some of their implications. We show that our canonical model of an insurance market can be reinterpreted to provide a model of loans with bankruptcy, or of work incentives. The properties that we uncover here have profound implications for the nature and existence of competitive equilibrium. We illustrate some of these. 3

${ }^{3}$ Because of space limitations, we provide a thorough analysis of the nature and existence of competitive equilibrium in a companion paper (Arnott and Stiglitz [1987a]). 


\section{Part I: Basic Analytics}

\section{The Model}

Throughout most of the paper we shall employ the simplest model in which moral hazard is present. Each individual in the economy engages in a single activity that has two possible outcanes, which we refer to as "accident" and "no accident".4 The output of the economy is a consumption good which is the only good in the economy. An individual's level of output (his consumption or income in the absence of insurance) depends on whether or not an accident occurs to him. The probability of an individual having an accident is a function of his accident-prevention effort, 5 and different individuals' accident probabilities are statistically independent. To isolate the phenomena arising from moral hazard (from those which would arise if there were adverse selection as well) we assume that individuals are identical. Alternatively, we could assume that insurers can observe all the relevant characteristics of the insured (except, of course, effort), and interpret our analysis as applying to a group with the same characteristics.

Because they are risk-averse, individuals will want to insure against the accident. We assume that whoever provides the insurance

${ }^{4}$ One may instead interpret the two outcomes as "large damage conditional on an accident occurring" and "small damage conditional on an accident cocurring."

5 our analysis is sufficiently general that effort may be interpreted variously as exertion, the time spent in accidentprevention activity, the nature (umpleasantness) of the accidentprevention activity undertaken, and (for some utility functions) units of the consumption good used up in accident prevention. 
can observe whether the accident has occurred, but neither the underlying states of nature nor individuals' effort levels--this is the informational asymmetry which gives rise to the moral hazard problem. Thus, insurance is provided against the accident. As more insurance is provided, the marginal private benefit to the indivicual of expending a given level of effort on accident prevention falls; as a result, he will tend to expend less effort which will increase the probability of his having an accident.

We denote by $Y_{0}$ and $Y_{1}$ consumption in the events no accident and accident, respectively. In the absence of insurance

$$
Y_{0}=w \quad Y_{1}=w-d,
$$

where $w$ is the no-accident output and $d$ the damage due to the accident, so that $w-d$ is the accident output. We characterize an insurance policy in terms of a net (of premium) payout or benefit, $\alpha$, which the individual receives in the event of accident, and a premium, $\beta$, which the individual pays if an accident does not occur. ${ }^{6}$ Thus, with insurance

$$
Y_{0}=w-\beta \quad \text { and } \quad Y_{1}=w-d+\alpha .
$$

The probability, $p$, that an accident oocurs to an individual is a function of his level of (accident-prevention) effort, $e$ - At some points in the paper, we shall assume that the individual has a choice of only a discrete number of effort levels, each corresponding to a different accident-prevention activity or technique. In this case, effort need not be quantified. We denote by $\mathrm{p}^{j}$ the probability of

6This corresponds to an insurance policy with $\beta$ payable in both events, and a gross payout in the event of accident of $\alpha+\beta$. 
accident when effort level $j$ is chosen, and by $\bar{p}$ the probability of accident when nothing is done to prevent the accident. 7 we assume that $\bar{p}<1-$ with no effort an accident need not occur.

At other points in the paper, we shall assume that the individual has a choice over a continum of effort levels. We assume that more effort always reduces the probability of accident and does so in a continuous manner, and we cardinalize effort in such a way that $e=0$ with zero effort and $p(e)$ is strictly convex and analytic for $e>0$. Thus, $\mathrm{p}^{\prime}(e)<0$ and $\mathrm{p}^{\prime \prime}(e)>0$ for $e>0$. For this case, too, we assume that $p(0) \equiv \bar{p}<1$. We refer to $p(e)$ as the probability-ofaccident function.

The individual's expected utility is

$$
E U=\left(1-p j^{j}\right) j_{0}\left(Y_{0}\right)+p j_{U} j_{1}\left(Y_{1}\right)
$$

in the discrete effort levels case, where $\mathrm{UJ}_{0}$ is the individual's utility function with effort $j$ if an accident does not occur, and $\mathrm{Uj}_{1}$ the corresponding utility function when an accident does occur. In the continum of effort levels case, expected utility is

$$
E U=(1-p(e)) U_{0}\left(Y_{0}, e\right)+p(e) U_{1}\left(Y_{1}, e\right) \text {. }
$$

We assume that $\frac{a U_{i}}{a \hat{a} y_{i}}>0$ and $\frac{a^{2} U_{i}}{a_{i}^{2}}<0, i=0,1$; i.e., in each

event and for every effort level, there is positive but diminishing marginal utility of consumption. For the contimum of effort

${ }^{7}$ We allow the individual to mix activities on the assumption that $p=\Sigma \varepsilon^{j} p^{j}$ where $\varepsilon^{j}$ is the proportion of "time" he devotes devotes to accident-prevention activity $j$. 
levels case we shall assume additionally that $\frac{a_{i}}{a ̈ e}<0$ and $\frac{\ddot{a}^{2} U_{i}}{a e^{2}} \leq 0,8$ but shall place no restrictions on $\frac{\ddot{a}^{2} U_{i}}{a ̈ y_{i}}$ äe .

In much of the subsequent analysis, it will prove insightful to focus on certain restricted classes of utility functions. Scmetimes we shall treat expected utility functions of the form

$$
E U=(1-p j) u_{0}\left(Y_{0}\right)+p j u_{1}\left(Y_{1}\right)-e^{j}
$$

in the discrete effort levels case, and

$$
E U=(1-p(e)) u_{0}\left(Y_{0}\right)+p(e) u_{1}\left(Y_{1}\right)-e
$$

in the continum of effort levels case. We refer to these as separable expected utility functions. Note that to go from (1.2a) to (1.2ai) and from (1.2b) to (1.2bi) requires three assumptions: first, that utility in both events is strongly separable in consumption and effort; second, that the disutility of effort is event-independent; 9 and thind, that effort is measured by the disutility it causes. For part of the analysis, we go further and assume that the utility-of-consumption function is also event-independent, that is $u_{0}(y)=u_{1}(y)$ for all $y$. The general theory requires, of course, neither the assumption of separability nor that of event-independence. our abjective is to show that even with these strong assumptions, the indifference curves and feasibility set will not be well-behaved.

\footnotetext{
${ }^{8}$ Since the cardinalization of $e$ has been chosen so that $p(e)$ is convex, this assumption is restrictive.

9This assumption and the previous one are natural if our model is interpreted as static, since normally we think of effort as occurring prior to the realization of the event and prior to consumption. These two assumptions are less reasonable if instead our model is interpreted as describing a stationary state.
} 
Unless specified otherwise, we assume separability. We consider same of the complications that arise with non-separable utility in sections 4 and 6.3 .

2. Ill-Behaved Consumers with Well-Behaved Utility Functions: The Peculiar Shape of Indifference arves

\subsection{Discrete effort levels.}

We define $v^{j}(\alpha, \beta)$ to be the expected utility as a function of $\alpha$ and $\beta$ when effort level $j$ is chosen in the discrete effort levels case, i.e., $\mathrm{v}^{j}(\alpha, \beta)=\left(1-\mathrm{p}^{j}\right) \mathrm{U}_{\mathrm{j}}(\mathrm{w}-\beta)+\mathrm{pj}_{\mathrm{U}}^{j_{1}}(\mathrm{w}-\alpha+\alpha) \equiv \mathrm{E} \mathrm{u}^{j}$. Let $\mathrm{v}_{\mathrm{j}} \mathrm{u}$ be the indifference curve in $\alpha-\beta$ space along which expected utility is $V_{u}$ with effort level $j$. From (1.2ai), with separability the slope of such an effort-fixed indifference curve at $(\alpha, \beta)$ is

$$
\left.\frac{d \beta}{d \alpha}\right|_{v_{u}^{j}}=-\left(\frac{a ̈ E U^{j} / a ̈ \alpha}{a E U^{j} / a \beta}\right)=\frac{u_{1}^{\prime} p^{j}}{u_{0}^{\prime}\left(1-p^{j}\right)} \equiv s^{j}(\alpha, \beta)>0,
$$

where $a^{\prime}$ denotes a derivative and $s^{j}$ is the marginal rate of substitution between $\alpha$ and $\beta$ with effort level $j$. The slope is positive because $\alpha$ is a good and $\beta$ is a bad. Let $A_{0}(\beta) \equiv-\frac{u_{0}^{\prime \prime}}{u_{0}^{\prime}}$ denote the (local) coefficient of absolute risk aversion in the no-accident event with premium $\beta$, and $A_{1}(\alpha) \equiv-\frac{u ̈}{u_{i}}$ denote the corresponding coefficient in the event of accident. Then the curvature of the effort-fixed indifference curve can be shown to be

$$
\left.\frac{d^{2} \beta}{d \alpha^{2}}\right|_{v_{u}^{j}}=-s^{j}\left(A_{1}+s^{j} A_{0}\right)<0
$$


Thus, effort-fixed indifference curves are strictly convex, reflecting the individual's aversion to risk. Also since $\alpha$ is a good and $\beta$ a bad, lower effort-fixed indifference curves are preferred. These results are shown in Figure 1. Insert Figure 1

We consider the case with two effort levels--high $(\mathrm{H})$ and low (L). From (1.2ai), with the arbitrary insurance package $(\hat{\alpha}, \hat{\beta})$ and associated consumption levels $\left(\hat{Y}_{1}, \hat{Y}_{0}\right)$, the individual's expected utility is

$$
v^{H}\left(\hat{Y}_{0}, \hat{Y}_{1}\right)=\left(1-p^{H}\right) u_{0}\left(\hat{Y}_{0}\right)+p^{H} u_{1}\left(\hat{Y}_{1}\right)-e^{H}
$$

with high effort, and

$$
v^{L}\left(\hat{Y}_{0}, \hat{Y}_{1}\right)=(1-p) u_{0}\left(\hat{Y}_{0}\right)+p u_{1}\left(\hat{Y}_{1}\right)-e^{L}
$$

with low effort. From (2.1)

$$
s^{H}(\hat{\alpha}, \hat{\beta})=\frac{u_{1}^{\prime}\left(\hat{Y}_{1}\right)}{u_{0}^{\prime}\left(\hat{Y}_{0}\right)}\left(\frac{p^{H}}{1-p^{H}}\right)<\frac{u_{1}^{\prime}\left(\hat{Y}_{1}\right)}{u_{0}^{\prime}\left(\hat{Y}_{0}\right)}\left(\frac{p^{L}}{1-p^{L}}\right)=s^{L}(\hat{\alpha}, \hat{\beta}),
$$

since $\mathrm{p}^{\mathrm{L}}>\mathrm{p}^{\mathrm{H}} \quad$ (with higher effort, the probability of accident is lower). At any point in $\alpha-\beta$ space, the low-effort indifference curve is steeper than the high-effort indifference curve since with lower effort the probability of accident is higher, and therefore to maintain the same level of utility, the individual requires a smaller increase in payout to compensate for a given increase in premium.

Individuals choose the effort level to maximize their expected utility. From (2.3a) and (2.3b) 


$$
\begin{gathered}
v^{H}\left(\hat{Y}_{0}, \hat{Y}_{1}\right) \gtreqless v^{L}\left(\hat{Y}_{0}, \hat{Y}_{1}\right) \\
\text { as } u_{0}\left(\hat{Y}_{0}\right)-u_{1}\left(\hat{Y}_{1}\right) \gtreqless \frac{e^{H}-e^{L}}{p^{L}-p^{H}} \equiv \ddot{Y}^{H, L} \text {. }
\end{gathered}
$$

Along $\phi^{\mathrm{H}, \mathrm{L}}$, which we refer to as the switching locus, individuals are indifferent between the two effort levels; i.e. $\phi^{\mathrm{H}, \mathrm{L}}$ is the locus of $(\alpha, \beta)$ such that $u_{0}\left(\hat{Y}_{0}\right)-u_{1}\left(\hat{Y}_{1}\right)=\ddot{y}^{H}, L$. Eq. (2.5) implies that at low levels of insurance (below $\phi^{\mathrm{H}, \mathrm{L}}$ ) individuals choose high effort, while at high levels of insurance they choose low effort, which accords with intuition. ${ }^{10}$

Insert Figure 2

We may now define an indifference curve with endogenous effort (hereafter simply indifference curve) corresponding to $\mathrm{V}=\mathrm{V}_{\mathrm{u}}$ to be the locus of $(\alpha, \beta)$ such that $\max \left(\mathrm{V}^{\mathrm{H}}(\alpha, \beta), \mathrm{V}^{\mathrm{L}}(\alpha, \beta)\right)=\mathrm{V}_{\mathrm{u}}$. Since individuals choose high effort for $(\alpha, \beta)$ below $\phi^{\mathrm{H}, \mathrm{L}}$ and low effort for $(\alpha, \beta)$ above $\phi^{\mathrm{H}, \mathrm{L}}$, then the indifference curve $\mathrm{V}_{\mathrm{u}}$ coincides with $\mathrm{V}_{\mathrm{u}}^{\mathrm{H}}$ below $\phi^{\mathrm{H}, \mathrm{L}}$ and $\mathrm{V}_{\mathrm{u}}^{\mathrm{L}}$ above it. From Figure 2, this implies that an indifference curve is the upper envelope of the corresponding effort-fixed indifference curves, and furthermore that it has an escalloped shape and is therefore not convex.

The above argument generalizes straightforwardly to the case where there is an arbitrary number of discrete effort levels. Hence, with separable utility, as more insurance is provided, the individual

$10_{\text {we }}$ assume that high effort is chosen with zero insurance. 
chooses successively lower levels of effort. Furthermore, indifference curves are not convex.

\section{2 continum of effort levels}

Expected utility is a function of $\alpha, \beta$, and e; i.e., $\mathrm{EU}=\mathrm{EU}(\alpha, \beta, e)$. We assume the individual chooses the level of effort taking $\alpha$ and $\beta$ as fixed; thus,

$$
e(\alpha, \beta)=\operatorname{argmax} \mathrm{EU}(\alpha, \beta, e) \text {, }
$$

which we refer to as the effort supply function. Substitution of (2.6) into $\mathrm{EU}(\alpha, \beta, e)$ yields $\mathrm{V}(\alpha, \beta)$, which gives expected utility as a function of the benefit and premium. We now investigate the properties of the corresponding indifference curves.

Using the envelope theorem, it follows from (1.2bi) that

$$
\left.\frac{d \beta}{d \alpha}\right|_{\bar{v}}=s \text { and }\left.\frac{d^{2} \beta}{d \alpha^{2}}\right|_{\bar{v}}=\left(-s\left(A_{1}+s A_{0}\right)\right\}+\left.\frac{r p^{\prime}}{(1-p)^{2}} \frac{d e}{d \alpha}\right|_{\bar{v}}, \quad(2.7 a, b)
$$

where $s \equiv \frac{p u_{1}^{\prime}}{(1-p) u_{0}^{\prime}}$ is the marginal rate of substitution between $\alpha$ and $\beta$ and $r \equiv u_{1}^{\prime} / u_{0}^{\prime}$ is the ratio of marginal utilities. The expression in curly brackets in $(2.7 \mathrm{~b})$ is negative, reflecting the observation made earlier that, with effort fixed, indifference curves would be strictly convex because of risk aversion (recall Figure 1). But increasing the amount of insurance decreases effort (we shall prove this shortly) and increases the probability of accident, which effect by itself causes indifferences curves to be concave; this is captured by the second term in (2.7b) which is positive $\left(\mathrm{p}^{\prime}<0, r>0\right.$, $\left.\left.\frac{d e}{d \alpha}\right|_{\bar{v}}<0\right)$. Thus, there is one effect causing indifference curves to be corvex, and another causing them to be concave. To 
ascertain which effect dominates requires evaluating $\left.\frac{\mathrm{de}}{\mathrm{da}}\right|_{\overline{\mathrm{V}}} \cdot$

Fran (1.2bi), the first-onder condition of the individual's maximization problem is

$$
e\left\{\left(-u_{0}\left(y_{0}\right)+u_{1}\left(y_{1}\right)\right) p^{\prime}(e)-1\right\}=0 .
$$

$\left(-u_{0}\left(y_{0}\right)+u_{1}\left(y_{1}\right)\right) p^{\prime}$ is the marginal private benefit of effort in utility terms, the decrease in the probability of accident times the gain in utility from not having an accident, while 1 is the marginal cost. Since $p^{\prime \prime}(e)>0$, the second-order condition is satisfied at any local extremum. Furthermore, where effort is positive, differentiation of (2.8) yields,

$$
\frac{a ̈ e}{\ddot{a} \alpha}=-\frac{u_{1}^{\prime}\left(p^{\prime}\right)^{2}}{p^{\prime \prime}}<0 \text { and } \frac{a ̈ e}{\ddot{a} \beta}=-\frac{u_{j}^{\prime}\left(p^{\prime}\right)^{2}}{p^{\prime \prime}}<0 .
$$

These equations inply that at any $(\alpha, \beta)$ where the effort chosen by the individual is positive, effort decreases as more insurance is provided until a point is reached beyond which effort is zero. This result is shown in Figure 3.

Insert Figure 3

Constant effort loci have slope and curvature

$$
\left.\frac{d \beta}{d \alpha}\right|_{\bar{e}}=-r \text { and }\left.\frac{d^{2} \beta}{d \alpha^{2}}\right|_{\bar{e}}=r\left(A_{1}-r A_{0}\right) \text {. }
$$

Finally, we define the zero effort line (ZEI) to be the locus of $(\alpha, \beta)$ satisfying

$$
\left(-u_{0}\left(y_{0}\right)+u_{1}\left(Y_{1}\right)\right) \lim _{e} p^{\prime}(e)-1=0 \text {. }
$$

Define $\ell$ to be the set of $(\alpha, \beta)$ for which effort is positive. Then, using $(2.7 a)$ and $(2.9 a, b)$, 


$$
\begin{aligned}
\left.\frac{d e}{d \alpha}\right|_{\bar{v}} & =\frac{\ddot{a} e}{\ddot{a} \alpha}+\left.\frac{\ddot{a} e}{\ddot{a} \beta} \frac{d \beta}{d \alpha}\right|_{\bar{v}} \\
& =\left\{\begin{array}{cc}
-\frac{\left(p^{\prime}\right)^{2}}{p^{\prime \prime}} \frac{u_{1}^{\prime}}{1-p}<0 & \text { for }(\alpha, \beta) \in \ell \\
0 & \text { for }(\alpha, \beta) \& \ell .
\end{array}\right.
\end{aligned}
$$

And combining $(2.12)$ and $(2.7 \mathrm{~b})$ yields

$$
\left.\frac{d^{2} \beta}{d \alpha^{2}}\right|_{\bar{v}}= \begin{cases}-s\left[\left(A_{1}+s A_{0}\right)+\frac{u_{1}^{\prime}\left(p^{\prime}\right)^{3}}{(1-p)^{2} p p^{\prime \prime}}\right] & \text { for }(\alpha, \beta) \in \ell \\ -s\left(A_{1}+s A_{0}\right) & \text { for }(\alpha, \beta) \& \ell .\end{cases}
$$

Eq. (2.13) implies that indifference curves are comvex beyond the zero effort line, but below the zero effort line effort may fall off sufficiently fast as more insurance is provided that the indifference curves are not convex. More specifically, the indifference curve at a point $(\alpha, \beta)$ is more likely to be nonconvex, the less risk-averse are individuals (the smaller $A_{1}$ and $A_{0}$ ), the more responsive the probability of accident to effort, and the lower the curvature of the $p(e)$ function.

Most of the applied literature on moral hazard conducts the analysis on the assumption (explicit or implicit) that indifference curves are convex. We have shown that doing so is restrictive.

Sample indifference curves are drawn in Figure 4. The slope Insert Figure 4 
discontinuity and subsequent nonoonvexity in $V_{0}$ at the zero effort line ocours if

$$
\lim _{\text {e } 0} \frac{\left(p^{\prime}\right)^{3}}{p^{\prime \prime}}=-\infty
$$

This condition relates to the curvature of the probability of accident function as effort goes to zero. An example in which this condition holds is $p=\bar{p}-e^{\epsilon}$ for small $e$ and $\epsilon<1 / 2$, for which

$$
\lim _{e \downarrow 0} \frac{\left(\mathrm{p}^{\prime}\right)^{3}}{\mathrm{p}^{\prime \prime}}=\lim _{\mathrm{e} \downarrow} \frac{\epsilon^{2}}{\epsilon-1} \mathrm{e}^{2 \epsilon-1}=-\infty
$$

\section{Price- and Income-Consumption Lines}

The possible nonconvexity of indifference curves implies that income- and price- consumption lines may be discontinuous.

\subsection{Two effort levels, income-consumption line}

We term $q \equiv \frac{\beta}{\alpha}$ (the premium/benefit ratio) the "price" of insurance. Then an income-consumption line (IC) corresponding to price $q$ is the locus of points of maximal utility on the family of (budget) lines $\beta=q\left(\alpha-\alpha_{0}\right)$ with $\beta \geq 0$ and $\alpha \geq 0$. An effort-fixed income-consumption line is defined analogously, but with effort fixed.

As in the previous section, to improve intuition, we first obtain the characteristics of the two effort-fixed income-consumption lines corresponding to slope $q$, and then determine how the corresponding income-consumption line is derived from the two effort-fixed income- 
consumption lines. ${ }^{11}$ The high-effort income-consumption line, denoted by $I C^{H}$, is given

$$
\frac{\left(u_{1}^{\prime}\right)^{H}}{\left(u_{0}^{\prime}\right)^{H}}\left(\frac{p^{H}}{1-p^{H}}\right) \equiv s^{H}=q \text {. }
$$

and its slope by

$$
\left.\frac{d \beta}{d \alpha}\right|_{I C^{H}}=-\frac{A_{1}^{H}}{A_{0}^{H}} .
$$

The formula for the low-effort income-consumption line and its slope are analogous.

We now show that the income-consumption lines may be discontinuous. We start with the situation shown in Figure 5, in which a line with slope $q$ is tangent to the same indifference curve at two points and meets the $\alpha$-axis at $\alpha_{0}^{\star}$. This is possible because the indifference curve has an escalloped shape. The lower tangency point corresponds to high effort, the higher one to low effort. Then we increase $\alpha_{0}$, shifting the line of slope $q$ to the right, and ascertain whether $\mathrm{V}^{\mathrm{H}}(\alpha, \beta)$ or $\mathrm{V}^{\mathrm{L}}(\alpha, \beta)$ increases faster along the respective effort-fixed income-consumption lines. suppose, for the sake of argument, that $V^{H}$ is increasing faster. Then in terms of

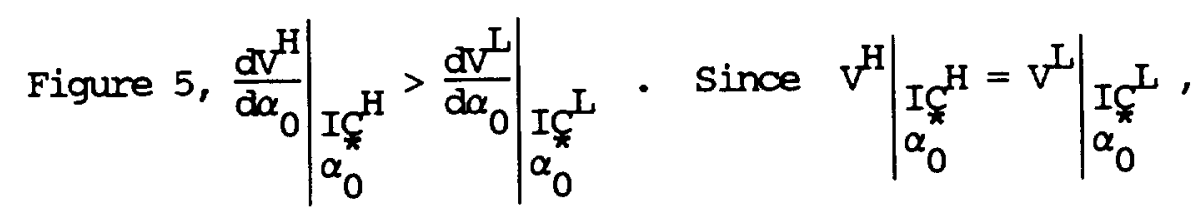

${ }^{11^{1}}$ o simplify exposition, we examine only those segments of income- and price-consumption lines for which $\alpha>0$ and $\beta>0$. 


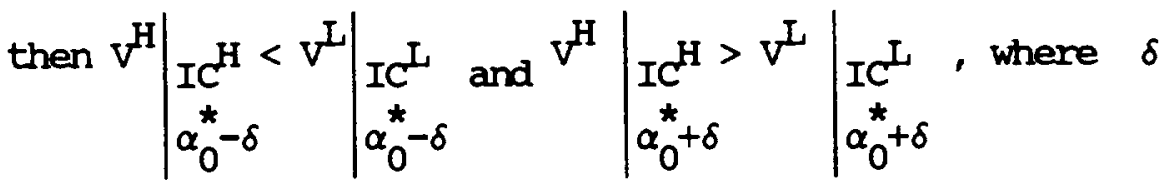

is an arbitrarily small positive number. This implies that the point of maximal utility along the line $\beta=q\left(\alpha-\left(\alpha_{0}^{\star}-\delta\right)\right)$ is on $I C^{L}$, while the corresponding point along the line $\beta=q\left(\alpha-\left(\alpha_{0}^{*}+\delta\right)\right)$ is on $I C^{H}$. Hence, in this case, the (effort-variable) incame-consumption line jumps dowrwards at $\alpha_{0}^{*}$, from $\left(\alpha^{\mathrm{L}}, \beta^{\mathrm{L}}\right)$ to $\left(\alpha^{\mathrm{H}}, \beta^{\mathrm{H}}\right)$, as $\alpha_{0}$ increases.

\section{Insert Figure 5}

It is straighforward to show that

$$
\left.\frac{d V^{j}}{d \alpha_{0}}\right|_{I c^{j}}=\frac{a V^{j}}{a} \alpha=p^{j}\left(u_{i}^{j}\right)^{j} \text {. }
$$

To understand this result, we may decompose the effect of the increase in $\alpha_{0}$. Prior to the increase, the individual was at $\left(\alpha^{j}, \beta^{j}\right)$. Then the initial effect of an increase in $\alpha_{0}$ by $d \alpha_{0}$ is to change the indivicual's insurance purchases to $\left(\alpha j+d \alpha_{0}, \beta^{j}\right)$ which increases his utility by $\left(u^{\prime}{ }_{1}\right)^{j} d \alpha_{0}$ with probability $p^{j}$, and hence his expected utility by $p^{j}\left(u_{1}\right)^{j} d_{d} \alpha_{0}$. The second effect results from movement from $\left(\alpha^{j}+d \alpha_{0}, \beta^{j}\right)$ to same other point on the budget line $\beta=q\left(\alpha-\left(\alpha_{0+} d \alpha_{0}\right)\right)$. Since the budget line at $\left(\alpha^{j}, \beta^{j}\right)$ is tangent to the indifference curve there, by the envelope theorem the second effect has no first-order impact on utility. It follows from (3.3) that

$$
\left.\left.\frac{d V^{H}}{d \alpha_{0}}\right|_{I C^{H}} \gtreqless \frac{d V^{I}}{d \alpha_{0}}\right|_{I C^{L}} \Leftrightarrow p^{H}\left(u_{i}^{\prime}\right)^{H} \gtreqless p^{L}\left(u_{1}^{\prime}\right)^{L} .
$$


Since $p^{H}<p^{L}$, while $\left(u^{\prime}\right)^{H}>\left(u_{1}^{\prime}\right)^{L}$ along a budget line, then it appears that the income-consumption line can jump either up or down at a point of discontimuity. It can be shown that such is indeed the case.

\subsection{Continum of effort levels, incame-consumption line}

similar arguments show that with a continum of effort levels, there may be discontinuities in the income-consumption line. Where $D$ and $D^{\prime}$ are the lower and upper points of a discontinuity in the income-consumption line, the line jumps down if $p^{D}\left(u_{1}^{\prime}\right)^{D}>p^{D^{\prime}}\left(u_{1}^{\prime}\right)^{D^{\prime}}$ and up if the inequality is in the opposite direction. In addition, we can show that there may be positivelysloped segments of the income-consumption line. The slope of the income-consumption line (except at the points of discontinuity) is

$$
\left.\frac{d \beta}{d \alpha}\right|_{I C}=-\frac{A_{1}+\frac{\left(p^{\prime}\right)^{3} u_{1}^{\prime}}{p^{\prime \prime} p(1-p)}}{A_{0}+\frac{\left(p^{\prime}\right)^{3} u_{0}^{\prime}}{p^{\prime \prime} p(1-p)}},
$$

which is positive if either the numerator or denominator is negative, but not both.

\subsection{Price-consumption line}

The price-consumption line $(\mathrm{PC})$ is the locus of $(\alpha, \beta)$ of maximal utility on the family of lines $\beta=g \alpha$ with $\beta \geq 0$ and $\alpha \geq 0$ (i.e., rays emanating from the origin in the positive orthant). We derive the effort-fixed price-consumption lines and then obtain the priceconsumption line with effort endogenous.

The price-consumption line with high effort denoted by $\mathrm{PC}^{\mathrm{H}}$, is the locus of points satisfying 


$$
\frac{\left(u_{i}^{\prime}\right)^{\mathrm{H}} p^{\mathrm{H}}}{\left(u_{0}^{\prime}\right)^{\mathrm{H}}\left(1-p^{\mathrm{H}}\right)}=\frac{\beta}{\alpha}
$$

and its slope is

$$
\left.\frac{d \beta}{d \alpha}\right|_{P C^{H}}=\frac{\beta}{\alpha}\left(\frac{1-\alpha A_{1}^{\mathrm{H}}}{1+\beta \mathrm{A}_{0}^{\mathrm{H}}}\right),
$$

from which we see that an effort-fixed price-consumption line can be positively-sloped. The low-effort equations are analogous.

We now investigate points of discontinuity in the priceconsumption line. Turn to Figure 6 . We start off with a situation in which a ray from the origin with slope $q_{0}$ is tangent to the same indifference curve at two points, the lower one corresponding to high effort and the upper one to low effort. The price-consumption line jumps upwards at this price if $\left.\frac{d v^{H}}{d q}\right|_{\begin{array}{l}P^{H} \\ q_{0}\end{array}}>\left.\frac{d V}{d q}\right|_{P^{L} C^{L}}$ and downwards

if the inequality is reversed. Proceeding as was done with income-consumption lines, we can show that the price-consumption line jumps upwards at a point of discontinuity if $\left(u^{\prime}\right)^{2} \mathrm{H}_{\mathrm{p}} \mathrm{H}_{\alpha} \mathrm{H}_{\alpha}<\left(u_{1}{ }^{\prime}\right) \mathrm{I}_{\mathrm{p}} \mathrm{I}_{\alpha} \mathrm{L}$, and downwards if the inequality is reversed. This inequality, too, can go in either direction. Hence, the price-consumption line can be discontinuous and can jump either up or down at a point of discontinuity. 
Similar results hold for the continum. 12

Finally, we note that the existence and properties of discontimuities in the price- and incame-consumption lines depend on global rather than local properties of the utility and probability-ofaccident functions. As a result, there appear to be no simple, primitive restrictions on these functions (except those which guarantee that indifference curves are everywhere convex) which guarantee that price- and/or income-consumption lines do not have discontinuities.

As we shall see later, the possibility of discontinuities in the price- and income-consumption lines has important implications for the existence and properties of competitive equilibrium.

In section 2, we examined the properties of indifference curves when the expected utility function is separable. We now briefly consider some of the complications that arise when this assumption is relaxed.

\section{Non-separable Utility Functions.}

The level of effort expended at accident avoidance may well affect the marginal rate of substitution between goods in the two events, given by

12 At interior points, the slope of the price-consumption line is

$$
\left.\frac{d \beta}{d \alpha}\right|_{p C}=-\frac{A_{1}+\frac{\left(p^{\prime}\right)^{3} u^{\prime}}{p^{\prime \prime} p(1-p)}-\frac{1}{\alpha}}{A_{0}+\frac{3}{p^{\prime \prime} p(1-p)}+\frac{1}{\beta}} .
$$


accident and no accident. This is obviously the case where "effort" is an expenditure of money, so that $u_{i}(y, e)=u_{i}(y-e)$. This greatly camplicates the analytics; we focus here on two interesting qualitative results which emerge-effort may not be monotonic in the amount of insurance, and in the contimum of effort levels case effort may not be a continuous function of the amount of insurance.

\subsection{Non-monotonic effort.}

The first result is seen mostly easily within the context of the discrete effort levels model. Here it is possible that $\mathrm{v}_{0}$ and $\mathrm{V}_{0}$ (defined as before, but now with non-separable utility) intersect more than once, as shown in Figure 7. If this occurs, then the individual will employ one level of effort at both high and low amounts of insurance and the other level at intermediate amounts. The intuitive rationale for this is that as the (compensated) amount of insurance provided increases, the marginal cost (disutility) of effort may fall faster than the marginal benefit. The boundary lines in $\alpha-\beta$ space between different activities can have almost any shape.

\section{Insert Figure 7}

\subsection{Discontinuous effort.}

We now show that with a continuum of effort levels, but a nonseparable utility function, effort may not be a continuous function of the amount of insurance, even though the underlying utility and probability-of-accident functions are "well-behaved." 
To see this, we write the first-order condition for effort (for an interior solution),

$$
\left(-U_{0}+U_{1}\right) p^{\prime}=-\left(\frac{\ddot{a} U_{0}}{\ddot{a} e}(1-p)+\frac{\ddot{a}_{1}}{a ̈ e} p\right) \text {. }
$$

The IHS is the marginal benefit of effort, and the RHS the marginal cost. Since

$$
\frac{\ddot{a}\left(\left(-U_{0}+U_{1}\right) p^{\prime}\right)}{\ddot{a} e}=\left(-\frac{\ddot{a} U_{0}}{\ddot{a} e}+\frac{\ddot{a} U_{1}}{\ddot{a} e}\right) p^{\prime}+\left(-U_{0}+U_{1}\right) p^{\prime \prime},
$$

the marginal benefit curve need not be downward-sloping. Increases in effort may increase the utility difference between the accident and no-accident events and hence increase the marginal return to further effort. Similarly, since

$$
-\frac{\ddot{a}\left(\frac{\ddot{a} U_{0}}{\ddot{a} e}(1-p)+\frac{\ddot{a}_{1}}{a ̈ e} p\right)}{\ddot{a} e}=-\frac{\ddot{a}^{2} U_{0}}{a e^{2}}(1-p)-\frac{\ddot{a}^{2} U_{1}}{\ddot{a} e^{2}} p+\left(\frac{\ddot{a} U_{0}}{\ddot{a} e}-\frac{\ddot{a} U_{1}}{\ddot{a} e}\right) p^{\prime},
$$

the marginal cost curve need not be upward-sloping. If the marginal cost to effort is lower in the no-accident event, more effort makes the no-accident event more likely, and hence may lower the marginal cost of effort. Thus, at any $(\alpha, \beta)$ there may be multiple local optimal effort levels.

The possibility of multiple local optimal effort levels for a given $(\alpha, \beta)$ considerably camplicates the analysis, since the effort level chosen by an individual may change discontinuously as $\alpha$ and $\beta$ are altered.

A geometric interpretation of this discontinuity is provided in Figure 8. Consider two fixed-effort indifference curves, corresponding to different levels of effort but the same level of utility, which intersect twice (in $\alpha-\beta$ space). Consider $\hat{e} \epsilon\left(e_{1}, e_{2}\right)$. If at 
$(\tilde{\alpha}, \tilde{\beta})$, EU is convex in $\mathrm{e}$, then $\mathrm{v}_{0}^{e_{1}}(\tilde{\alpha}, \tilde{\beta})=\mathrm{v}_{0}^{\mathrm{e}_{2}}(\tilde{\alpha}, \tilde{\beta})>$ $\mathrm{v}^{\boldsymbol{e}}(\tilde{\alpha}, \tilde{\beta})$. At $(\tilde{\alpha}, \tilde{\beta})$, effort will switch discontinuously between $e_{1}$ and $e_{2}$. If, however, EU is concave in $e$ at $(\tilde{\alpha}, \tilde{\beta})$, then there can be no such discontinuity.

Insert Figure 8

5. Implications for Demand Functions.

Quasi-concavity of indifference maps is important in conventional theory because without it, demand functions are discontinuous. The analysis of section 3 can be interpreted as establishing that if insurance firms offer individuals "linear" or price insurance contracts--a payment of $\alpha$ with premium $\alpha q$-the demand for insurance (and hence effort) may be discontinuous in $q$. It is also easy to establish that the demand function for insurance may be discontinuous in other prices (e.g. the cost of automobile repairs) as well.

Furthermore, an increase in the price of insurance can lead to a discontinuous increase in insurance purchased (and a corresponding discontinuous decrease in effort) rather than the expected decrease. 13

\section{The Badly-Behaved Zero Profit Locus}

In this section, we show that with moral hazard the set of feasible contracts, those at which profits are non-negative, which we term the feasibility set, is never convex. We focus our attention on

13With separable utility functions, insurance purchases decrease with the price of insurance and effort increases, except at points of discontinuity in the price-consumption line. This property does not extend to non-separable utility functions. These results can be obtained straightforwardly from differentiation of the first-order conditions of the individual's effort choice problem. 
the shape of the outer boundary of the set, which we refer to as the resounce constraint or, where appropriate, the zero profit locus (ZPL). We again divide the analysis into two cases, one with two activities, the other with a continum of effort levels.

\subsection{Two effort levels, separable utility.}

When high effort is expended, the effort-fixed zero profit locus is

$$
\beta\left(1-p^{H}\right)-\alpha p^{H}=0 \text { ， }
$$

which is a ray from the origin with slope $\frac{p^{H}}{1-p^{H}}$. Zero profits are made when the ratio of the premium to the net payout, which we have termed the price of insurance, equals the probability of accident divided by the probability of no accident. When low effort is expended, the corresponding effort-fixed zero profit loucs is a ray fram the origin with slope $\frac{p^{L}}{1-p^{L}}$. Since with low effort, the probability of accident is higher, a higher price must be charged for insurance to break even. The effort-fixed zero profit loci are shown in Figure 9.

Insert Figure 9

We now derive the zero profit locus with effort endogenous. Define the feasibility set contingent on high effort to be the set of $(\alpha, \beta)$ for which expected profits are non-negative when high effort is expended, and denote it by $\xi^{H}$. And let $f$ be the set of $(\alpha, \beta)$ for wich the individual chooses high effort; it was shown in section 2 that this is the area below $\phi^{\mathrm{H}, \mathrm{L}}$. Define $\mathcal{F}^{\mathrm{L}}$ and $\mathcal{L}$ accordingly for low effort, and 7 to be the feasibility set with effort endogenous. A point $(\alpha, \beta)$ is in $\mathcal{F}_{\text {if }}$ either it is in $\mathcal{F}^{\mathrm{H}}$ and the 
indivicual expends high effort there or it is in $7^{L}$ and the individual expends low effort there; i.e. $F=\left(F^{\mathrm{H}} \cap \mathcal{F}\right) \cup\left(\mathcal{F}^{\mathrm{L}} \cap \mathcal{L}\right)$. The feasibility set with effort endogenous is shown by the crosshatched area in Figure 9. The zero profit locus with effort endogenous is the boundary of $F$. From the Figure, it is clear that the feasibility set with effort endogenous is not convex.

\subsection{Continum of effort levels, separable utility.}

The zero profit locus is

$$
\beta(1-p(e))-\alpha p(e)=0 .
$$

Its slope is given by

$$
\left.\frac{d \beta}{d \alpha}\right|_{\text {ZPL }}=\frac{p+(\alpha+\beta) p^{\prime} \frac{\ddot{a} e}{\ddot{a} \alpha}}{(1-p)-(\alpha+\beta) p^{\prime} \frac{\ddot{a} e}{\ddot{a} \beta}} .
$$

Substituting $(2.9 a, b)$ into (6.3) gives

$$
\left.\frac{d \beta}{d \alpha}\right|_{z \mathrm{PL}}= \begin{cases}\frac{p-\frac{(\alpha+\beta) u_{1}^{\prime}\left(p^{\prime}\right)^{3}}{p^{\prime \prime}}}{(1-p)+\frac{(\alpha+\beta) u_{0}^{\prime}\left(p^{\prime}\right)^{3}}{p^{\prime \prime}}} & \text { for }(\alpha, \beta) \in \ell \\ \frac{\bar{p}}{1-\bar{p}} & \text { for }(\alpha, \beta) \notin \ell\end{cases}
$$

Several properties of the zero profit locus for this case are generally worthy of note.

1. The zero profit locus is continuous.

2. The curvature of the zero profit locus depends on third derivatives of the probability-of-accident function, restrictions on which have no persuasive economic justification.

3. There are nonetheless restrictions on the feasible shape of the 
zero profit locus. First, beyond the zero effort line, the zero profit loous is $\beta(1-\bar{p})-\alpha \bar{p}=0$. Second, the zero profit locus includes the origin and has a slope $\frac{p(e(0,0))}{1-p(e(0,0))}$ there. ${ }^{14}$ And thind, all points on the line segment joining a point in on the zero profit locus and the origin must lie in the feasibility set. 15 Relatedly, at any point on a positively-sloped segment of the zero profit locus at which effort is positive, the ZPL is steeper than the ray joining the origin to that point. 16 And fourth, the zero profit locus can have an infinite slope and backward-bending segments, but cannot have zero slope. 17

${ }^{14}$ Furthermore, with separable and event-independent utility, the slope of the ZPL at the origin exceeds the slope of the indifference curve there (recall (2.7)) .

${ }^{15}$ Label the point on the ZPL $\left(\alpha_{0}, \beta_{0}\right)$ and a point on the line segment $\left(\alpha_{1}, \beta_{1}\right)$. Both have the same price of insurance, but since effort decreases as one moves out along the line segment, the probability of accident is higher at $\left(\alpha_{0}, \beta_{0}\right)$ than at $\left(\alpha_{1}, \beta_{1}\right)$. since zero profits are made at $\left(\alpha_{0}, \beta_{0}\right)$, positive profits must be made at $\left(\alpha_{1}, \beta_{1}\right)$.

16 The slope of the zero profit locus is given by $\left(6.3^{\prime}\right)$, that of a line joining the origin to the point $(\alpha, \beta)$ on the $\mathrm{zPL} p(e(\alpha, \beta)) /(1-$ $p(e(\alpha, \beta))$.

17 Consider increasing $\beta$ from some point on the ZPL, holding $\alpha$ fixed. This has an ambiguous effect on profits. The increase in $\beta$, with effort constant, increases profits. But the increase in $\beta$ with $\alpha$ constant, lowers effort which effect by itself causes profits to fall. When the former effect dominates, the ZPL is positively-sloped; when the latter dominates it is negatively-sloped; and when the two are offsetting, it is infinitely-sloped.

Now consider increasing $\alpha$, holding $\beta$ constant. Both effects operate to decrease profits, which implies that the ZPL cannot have a zero slope. 
4. The feasibility set is never convex. 18

\subsection{Continum of effort levels, non-separable utility.}

We have seen that non-separability of the expected utility function can cause effort to be discontinuous in the parameters of the insurance contract. This can result in the feasibility set not being connected, and in points on the boundary of the feasibility set having positive profits.

\section{Part II: Implications}

In this part of the paper, we undertake two tasks: First, we show that the fact that both indifference curves and the feasibility set are "badly behaved" has strong implications for the existence and nature of equilibrium; and second, we illustrate that our analysis of insurance markets can be directly applied to other markets, including credit and labor markets.

\section{Existence and Properties of Equilibrium}

A thorough analysis of the existence and properties of equilibrium turns out to be remarkably complex, even for the simplest case of

18.The slope of the ZPL beyond the zero effort line is $p(0) /(1-$ $p(0))$, while at the origin it is $p(e(0,0)) /(1-p(e(0,0))$, which is smaller. Hence, a necessary condition for the feasibility set to be convex is that $\frac{\beta}{\alpha}$ at the point of intersection of the ZPL and the ZEL be strictly less than $\frac{p(0)}{1-p(0)}$. But since the point is on the $\mathrm{ZPL}, \frac{\beta}{\alpha}=\frac{\mathrm{p}(0)}{1-\mathrm{p}(0)}$ there. 
separable, event-independent utility. A reasonably camplete analysis is provided in Arnott and Stiglitz [1987a]. Here our aim is to use the gecmetric and analytic tools developed thus far in the paper to illuminate some of the issues involved. To simplify, we continue to assume separable utility.

The existence and properties of equilibrium are crucially dependent on what information is available to insurance firms. There are three items of information of concern to an insurance firm when insuring a client: i) whether or not the accident actually occurred; ii) the effort undertaken by the client to prevent the accident; and iii) if effort is not observable, the client's purchases of insurance from other firms.

In our analysis, we have assumed, and shall continue to assume, that firms cannot observe their clients' accident-prevention effort at all, 19 and can observe perfectly and without cost whether an accident cocurred.

With respect to the other item of information, we treat only the two extremes: i) where a firm can costlessly observe its clients' insurance purchases from other firms-we term this the "observable insurance purchases" case or simply the "observability" case; and ii) where a firm cannot observe its clients' purchases from other firms, the "unobservable insurance purchases" or "unobservability" case. This information is relevant since in the former case the firm can ration its clients' purchases of insurance, whereas in the latter it cannot.

19HBlmstrom [1979] considers the case in which firms can observe their clients' effort with noise. 
The existence and properties of equilibrium also depend on what insurance contracts are deemed admissible. The set of admissible contracts clearly depends on what is observable; if the quantity of insurance purchased at other firms is not observable, then admissible contracts cannot directly restrict the amount purchased at other firms. But there may be other restrictions on the set of admissible contracts which are motivated by other considerations: Should negative insurance 20 or random insurance ${ }^{21}$ be allowed? Should latent policies-policies which are not purchased in equilibrium but serve to deter entry--be permitted? The nature of equilibrium turns out to depend critically on the answers to such questions. When the set of admissible contracts is expanded, not only may there be new equilibria, but also the newly-admissible contracts may upset the original equilibria (this cocurs, for example, when the set of admissible contracts is expanded from price contracts to price and quantity contracts). It is our view that what contracts should be treated as admissible depends on context (and in particular, on transactions costs). 22

20 Where the individual pays when an accident occurs and receives a payout when it does not.

${ }^{21} 1_{\text {Arnott }}$ and Stiglitz [1987b] discuss random insurance with observability of insurance purchases.

22For instance, negative insurance requires verifying that an accident has not occurred, which may be far more costly than verifying that one has occurred; randomization may require verification that the firm is in fact randomizing acoording to the specified probabilities, again a task which is far harder than simply verifying that it pays a given amount in a given situation. 


\subsection{Observability: exclusive contract equilibrium.}

When it is feasible for firms to restrict the quantity of insurance (in particular, if the quantity of insurance which an individual buys is abservable), equilibrium will be characterized by exclusive contracts, in which the individual will purchase all of his insurance from a single provider. The equilibrium is at the point of maximm utility on the feasibility set.

\section{Insert Figure 10}

Figure 10 shows three possible exclusive contract equilibria for the two activities case-- $\theta^{\prime}, \theta^{\prime \prime}, \theta^{\prime \prime \prime}$. At $\theta^{\prime \prime}$, the point of intersection of the high effort zero profit locus and the switching locus, the individual would like to purchase more insurance at the going price $\left(\mathrm{p}^{\mathrm{H}} /\left(1-\mathrm{p}^{\mathrm{H}}\right)\right)$ but were the firm to offer additional insurance, he would switch to a low level of effort, and the policy would make a loss. This result extends to the case where there is a continum of effort levels. We showed in the previous section that at any point on a positively-sloped segment of the ZPL at which effort is positive, the ZPL is steeper than the price line joining the origin to that point. This establishes that competitive equilibrium will normally entail rationing of insurance, when it is feasible, as well as positive effort and partial insurance (i.e., $u^{\prime}{ }_{0}>u^{\prime}{ }_{1}$ ).

\subsection{Price equilibrium}

A second form of equilibrium, which is relevant with unobservability, is that where insurance firms simply offer price 
contracts, and do not restrict the quantity of insurance. our earlier analysis can be used to derive several important results.

A zero profit price equilibrium, if it exists, must be at the intersection of the zero profit locus and the price-consumption line. Because the price-consumption line may jump across the zero profit locus (recall section 3), a zero profit price equilibrium may not exist.

When the zero profit price equilibrium exists, the level of effort is zero with accidents which decrease or leave unchanged the marginal utility of income at each level of inoome. This follows from the fact that in a price equilibrium, individuals set the price, $q$, equal to their marginal rate of substitution:

$$
q=u^{\prime} 0 \mathrm{p} /\left(u^{\prime}{ }_{1}(1-p)\right),
$$

while from the zero profit condition

$$
\mathrm{q}=\mathrm{p} /(1-\mathrm{p})
$$

Hence, $u_{0}^{\prime}=u_{1}^{\prime} ;$ i.e. there is full insurance at the zero profit price equilibrium. This implies that if accidents decrease or leave unchanged the marginal utility of income, then

$$
u_{0} \leq u_{1}
$$

which in turn implies, from the first-order condition for effort, (2.8), that effort must be zero and that the equilibrium price is $q^{*}=\frac{p(0)}{1-p(0)}$.

We now identify a set of sufficient conditions for the nonexistence of a zero profit price equilibrium. Define the full insurance line (FIL) to be the locus of $(\alpha, \beta)$ for which $u^{\prime}{ }_{0}=u^{\prime}{ }_{1}$. From the above discussion it follows that if a zero profit price 
equilibrium exists, it lies at the point of intersection of the ZPL and the FIL; we label this point E. Now suppose that: i) the expected utility function is event-independent; ii) $\lim _{\text {elo }} \frac{p^{\prime}(e)^{3}}{p^{\prime \prime}(e)}=-\infty$; and $i$ ii) $\lim p^{\prime}(e)=-\infty$. From (iii) and (2.11), it follows that the elo

zero effort line is characterized by $u_{0}=u_{1}$. Furthermore, with event-independent utility, the ZEL and FIL coincide and satisfy $\alpha+\beta=d$. A necessary condition for $E$ to be an equilibrium is that the indifference curves be convex near $\mathbf{E}$. But we have already seen, that under condition (ii), indifference curves are nonconvex in the neighborhood of the zero effort line, and that $E$ is on the zero effort line.

Two further points should be noted. First, convexity of the indifference curves near $E$ does not ensure the existence of a zero profit price equilibrium; to establish existence, a global analysis is required. Second, the non-existence of a zero profit price equilibrium does not imply the non-existence of a price equilibrium. In Arnott and. Stiglitz [1987a] we show that a price equilibrium always exists, but may entail zero insurance or positive profits.

\section{3 other equilibrium forms.}

The fact that an insurance firm cannot observe insurance purchases from other firms does not mean that equilibrium must be a price equilibrium. Since the insurance firm can observe its own sales of insurance to an individual, by insisting that the individual purchase a large quantity, it can attempt to discourage the individual from purchasing from other firms. We refer to equilibria in which firms 
offer only quantity contracts as Q-equilibria, and equilibria in which some firms offer price contracts and other quantity contracts as PQequilibria. In Annott and Stiglitz [1987a] we show that Q-equilibria and PQ-equilibria may not exist; that is, given any set of insurance contracts, each of which at least breaks even, there exists a new contract which if offered would be purchased and make a profit. (The entry of this new contract would, however, result in other

firms making a loss.) The non-existence of equilibrium hinges critically on the properties of the income-consumption lines.

To see this, assume that utility is separable and eventindependent and consider the situation where there is a single incumbent firm in the market which offers a quantity policy. When can this be an equilibrium? If the incumbent's policy lies strictly inside the feasibility set, there exists a small, supplementary policy (possibly with negative insurance) which would be bought and be profitable. Thus, the incumbent's policy must lie on the ZPL . The incumbent's policy must also lie on the price-consumption line. Suppose, to the contrary, that the incumbent offers the policy G which lies on the ZPL but not on the price-consumption line, as illustrated in Figure 12. Then the supplementary policy GA will be purchased (since $A$ is below the indifference curve through $G$ ); and 
if $G A$ is small enough, it will make a profit, because the effort at $A$ is only slightly lower than at $G$ but the implicit price of policy $G A$ is significantly higher than that of $G$. Since profits at $A$ are negative, while the supplementary policy makes a profit, policy $G$ makes a loss. Thus, if equilibrium exists with a single inambent firm offering a quantity policy, the policy must lie at the point of intersection of the ZPL and the price-consumption line. If the priceconsumption line does not intersect the ZPL, such an equilibrium does not exist. If the price-consumption line does intersect the ZPL, it does so at the point $\mathrm{E}^{23}$, and $\mathrm{E}$ may be a Q-equilibrium. A necessary condition for $E$ to be a Q-equilibrium is that no part of the incomeconsumption line corresponding to the price $q^{*}=\frac{p(0)}{1-p(0)}$ below (i.e., corresponding to a higher utility level) $\mathrm{E}$ lies in the interior of the feasibility set. This is illustrated in Figure 12.

The contract B is preferred to $E$, and since $B$ lies on the income-consumption line corresponding to price $q^{*}=\frac{p(0)}{1-p(0)}$, the individual will prefer B to B plus E. Since also policy $B$ by itself is profitable, it upsets $\mathbf{E}$.

\section{Insert Fiqure 12}

When we further modify the analysis to allow for latent policies, a much richer set of equilibria emerges; and the set of equilibria includes positive profit equilibria.

\section{Applications}

${ }^{23}$ Recall that the point $E$ is the point of intersection of the zero profit locus and the full insurance line, and that when the priceconsumption line intersects the zero profit locus, it does so at $\mathrm{E}$. 
We have cast our presentation of the basic analytics of moral hazard in the context of an explicit insurance market. In this section, we wish to show that, with only a transformation of variables, the analysis can be employed to cast light on issues in the principal -agent literature. Though the basic framework of our analysis can be applied in many contexts, the appropriate equilibrium concept (the set of admissible contracts) may well differ, because what is easily observable in one market may not be so easily observable in another; e.g., while it may be possible to restrict insurance purchases from other firms, it may not be possible to restrict employment with other employers, or borrowing from other creditors. In the discussion below, we show how the model can be reinterpreted to investigate sharecropping and credit contracts, but we do not consider the appropriate equilibrium concept for each of the markets.

First, consider the contract between a risk-neutral landlord and a risk-averse laborer (e.g., Stiglitz [1974]) in a competitive market. Should the laborer: i) rent the land, thereby receiving output less rent; ii) be paio a straight wage for farming the land; or iii) share output with the landlord? The output from the land is a random variable and (in the sense of first-order stochastic dominance) increases with the laborer's effort. Moral hazard arises in the contract because the landlord is unable to observe the laborer's effort. Suppose, for purposes of exposition, that there are only two output levels, with the probability of the higher output level increasing in the laborer's effort. Let $x^{H}$ and $x^{L}$ denote the high and low outputs respectively; $R$ denote the landlord's required average 
return on the land; $Y^{H}$ and $y^{L}$ denote the tenant's consumption in the high- and low- output events, respectively; and e denote the tenant's effort. Then with the transformation of variables $x^{H}-R \leftrightarrow-w, x^{H L}$ $x^{L}<-d, y^{H} \ll->-\beta, y^{L}<->-\alpha+\alpha$, the problem is identical to the one analyzed in the paper. The rental contract corresponds to no insurance, the wage contract to full insurance, and sharecropping to partial insurance. our earlier result that, where exclusivity can be enforced, partial insurance is typical in equilibrium, corresponds to the result in the current context that, where the landlord can be sure that the worker will not obtain insurance against output variability from a third party, sharecropping will typically oocur.

second, consider the standard credit contract (e.g., Stiglitz and Weiss [1981]). The borrower obtains money from the lender and uses only this money to finance a project. The project is either successful, yielding return $R$, or unsuccessful, yielding a return of zero. Moral hazard occurs because the probability of success depends on the effort of the borrower, which is unobservable to the lender. The borrower starts with wealth $W$. We contrast the consequences of a limited liability loan, with collateral $c$ and interest rate $i$, with an unlimited liability loan with rate of interest $\rho$. The limited liability loan increases consumption in the event that the project is unsuccessful, but because $i>p$, it reduces consumption in the event the project is sucocessful. Thus, the limited liability loan is essentially an unlimited liability loan combined with insurance. With the transformation, $w+R-L(1+p)<->w, R<->d$, 
$W+R-L(1+i)<->w-\beta, W-C,<->w-\alpha+\alpha$, the problem is identical to the insurance problem analyzed in the paper. In the insurance context, the exclusive contract equilibrium always (with separable, eventindependent utility) entails positive insurance. The analogous result here is that a limited liability loan always dominates an unlimited liability loan. Another analogous result is that if the lender can enforce exclusivity (in this context, can ensure that the borrower does not obtain an additional loan, or additional insurance against the failure of the project, from a thind party) the equilibrium contract will entail credit rationing, in the sense that at the implicit price of insurance $q=\frac{(i-\rho) L}{L(1+\rho)-C}$, the borrower would like to obtain a larger loan, but is unable to find a lender who will agree to this.

A similar analysis holds if instead of choosing an effort level, the borrower has a choice of the riskiness of the two projects, both of which require an investment $L$. One project has, say, a higher return if successful, but a lower probability of success. We assume that the magnitude of the return cannot be observed (otherwise, in those cases where the project was successful, the lender could infer what project the borrower had undertaken). If the borrower undertakes the safe(s) project, his expected utility is

$$
U\left(W+R^{S}-L(1+i)\right)\left(1-p^{s}\right)+U(W-C) p^{s},
$$

while if the borrower undertakes the risky (r) project, his expected utility is

$$
U\left(W+R^{r}-L(1+i)\right)\left(1-p^{r}\right)+U(W-C) p^{r},
$$


where $p$ is the probability of the project failing. The fixedproject indifference curves, shown in Figure 13, are well-behaved. We can define the switching locus along which the individual switches from the safe to the risky project, $\phi^{s, r}$. Above the line (low collateral), the individual undertakes the risky project. The zero profit locus for the bank is that where the expected return to the loan $(1-p) i L-p(L-C)$ is equal to the opportunity cost of funds, $\rho L$. As drawn, the equilibrium, $z$, will be characterized by rationing and an exclusive contract, where feasible. Since the implicit price of insurance is

Insert Figure 13

$q=\frac{(\bar{i}-p) \bar{L}}{L(1+\rho)-C}$, while the implicit quantity is $L(1+\rho)-C$,

rationing has several behavioral implications. Not only is the borrower unable to obtain as large a loan as he would like at the actuarially fair price, but he is also unable to obtain the equilibrium loan with less collateral. Furthermore, even though there is an excess demand for loanable funds, lenders will not respond by raising the interest rate, $i$, since doing so has adverse incentive effects.

\section{Concluding comments}

If one believes, as we do, that incentive/moral hazard problems are pervasive in our economy, then it is important to construct models exploring the existence and properties of market equilibrium taking these problems into account. It would be nice if we could simply assume that the relevant functions had the necessary mathematical 
properties to allow a convenient borrowing of concepts, methods, and results from standard campetitive equilibrium analysis. Such, unfortunately, does not turn out to be the case.

The objective of this paper has been to develop the basic analytics of the economics of moral hazard. In spite of making standard convexity assumptions concerning the underlying utility functions and technology, we have established that insurance indifference curves are in general not convex and feasibility sets are never convex. Effort may change discontinuously as the parameters of the insurance contract are varied. And even when strong conditions are imposed on the forms of the underlying functions, price-consumption and income-consumption lines as well as demand curves may exhibit discontinuities.

We have suggested that these "perversities" have some profound implications for the existence and nature of equilibrium. For instance, equilibrium will be characterized by exclusive contracts entailing quantity rationing, when these are enforceable. When they are not, other contract forms will be seen. When only price contracts are offered, there may be no equilibrium with insurance in which firms make zero profits. And when each firm rations the quantity of insurance it sells, but cannot observe the quantities sold by other firms, no equilibrium may exist.

Though we have couched our analysis in terms of insurance markets, the results have a direct bearing on all markets in which uncertainty and incentive problems are both present; we illustrated this by showing how the model can be adapted to analyze labor and credit markets. The 
further investigation of the pervasive perversities which we have uncovered here, and their implications for equilibria under a variety of institutional settings, remain issues for future research. 


\section{Appendix: A Brief Review of the Earlier Literature}

It is umusual to have a literature review at the end of a paper. However, this paper is self-contained, and it is easier to explain here what contribution earlier papers made.

Pauly [1974] presented the basic two-outoomes moral hazard model. He assumed event-independent utility and convexity of indifference curves in $\alpha-\beta$ space. He identified and explained the exclusive contract equilibrium with observability and the zero profits price equilibrium with unobservability.

Helpman and Laffont [1975] broke new ground in recognizing the non-convexities to which moral hazard can give rise. For the n-outcome case, they proved the existence of an exclusive contract equilibrium with observability, and of a zero profit price equilibrium with unobservability when indifference curves are convex in the analog to $\alpha-\beta$ space. They also presented an example demonstrating the nonexistence of a zero profit price equilibrium with unobservability when indifference curves are non-convex. They did not, however, investigate the non-existence problem further, or consider alternative equilibrium concepts.

Most of the subsequent literature has focussed on the principalagent problem with a continum of outcomes, on the assumptions of convex indifference curves and continuity of effort in the parameters of the insurance contract.

Stiglitz [1983] provided an overview of the authors' preliminary work on moral hazard and introduced the analysis of price equilibria. Hellwig [1983] argued that in the case of unobservability of insurance purchases, there is a considerably larger set of candidate equilibria 
than the price equilibria; in particular, he considered Q-equilibria and some forms of PQ-equilibria for the case of two discrete effort levels. 


\section{BIBLIOGRAPHY}

Amott, R.J., and J.E. Stiglitz, "The Welfare Economics of Moral Hazard," Queen's University Institute for Economic Research, Discussion Paper \#635, (1986b).

Arnott, R.J., and J.E. Stiglitz, "Equilibrium in Competitive Insurance Markets with Moral Hazard," mimeo. (1987a).

Arnott, R.J., and J.E. Stiglitz, "Randomization with Asymmetric Information," mimeo. (1987b).

Hellwig, M.F., "On Moral Hazard and Non-Price Equilibrium in Competitive Insurance Markets," University of Bonn, Discussion Paper \#109, (1983).

Helpman, E., and J. J. Laffont, "On Moral Hazard in General Equilibrium," Journal of Economic Theory, 10(1975), 8-23.

H8lmstrom, B., "Moral Hazard and Observability," Bell Journal of Economics, 10(1979), 74-91.

Pauly, M. "Overprovision and Public Provision of Insurance," Quarterly Journal of Economias 88, 1974, 44-61.

Stiglitz, J.E., "Incentives and Risk Sharing in Sharecropping," Review of Economic Studies, XII (1974), 219-255.

Stiglitz, J.E., "Risk, Incentives and Insurance: The Pure Theory of Moral Hazard," The Geneva Papers, 8(1983), 4-32.

Stiglitz, J.E., and A. Weiss, "Credit Rationing in Markets with Imperfect Information," American Economic Review, 71, (1981), 393-410. 


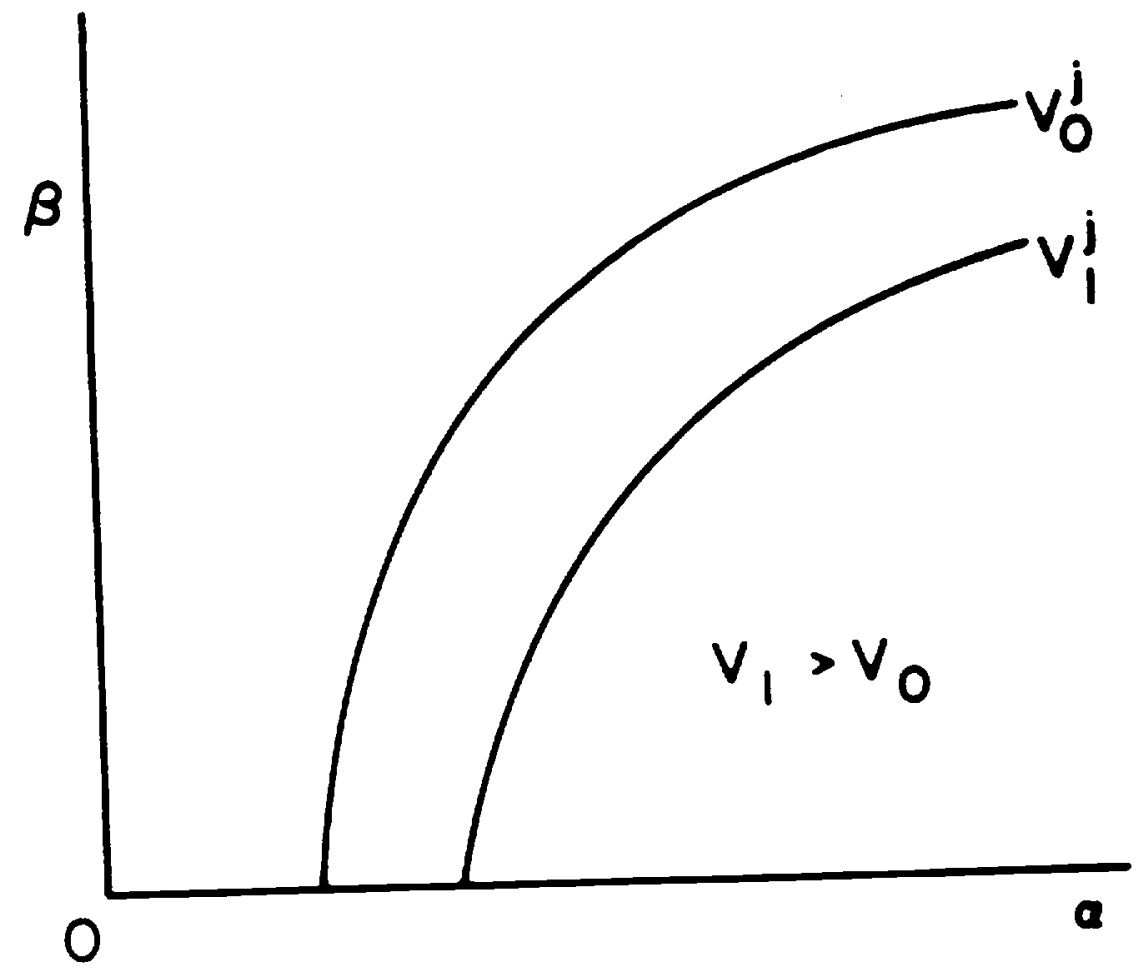

Figure 1: For a fixed level of effort, indifference curves are convex. Lower indifference curves correspond to higher levels of utility. 


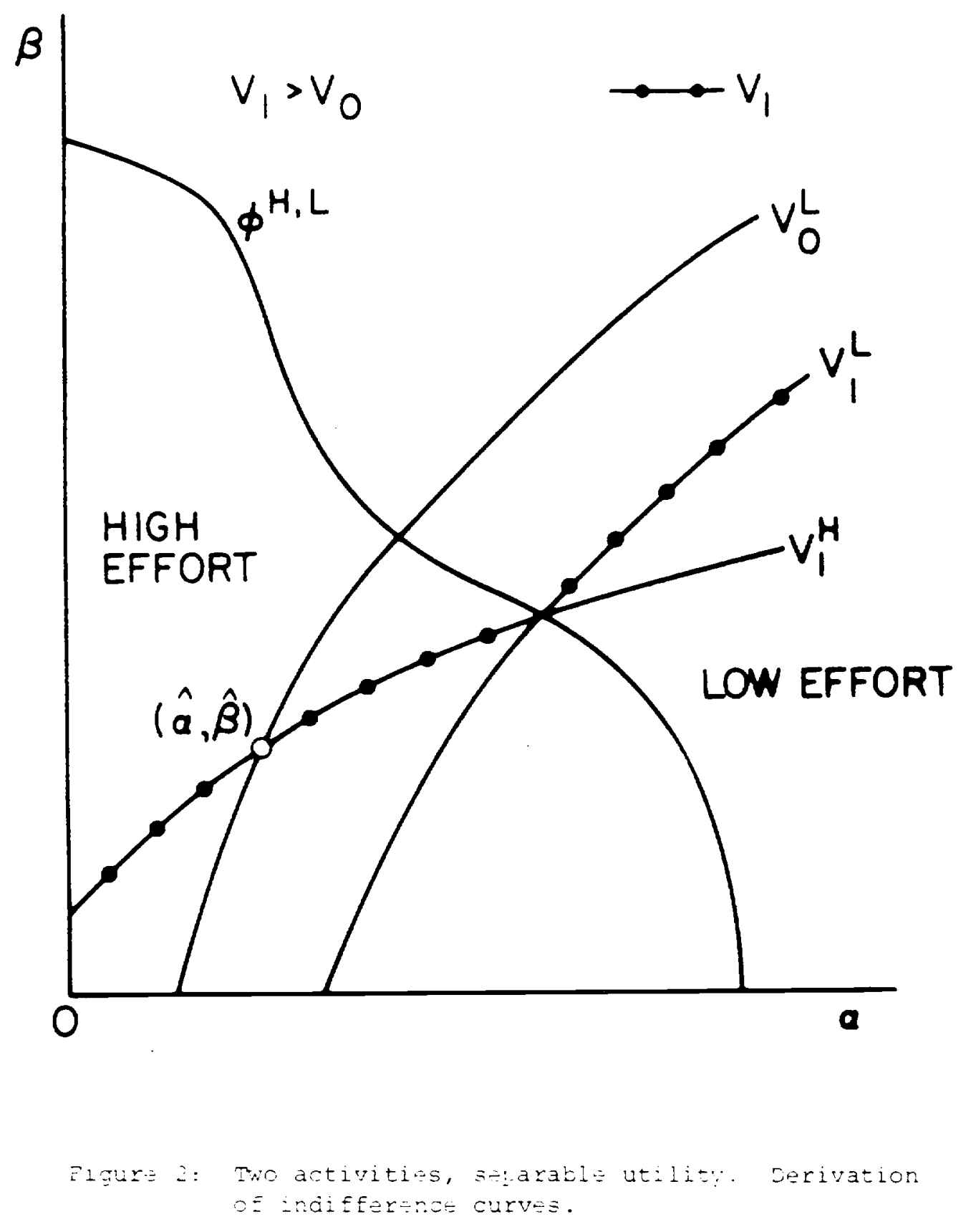




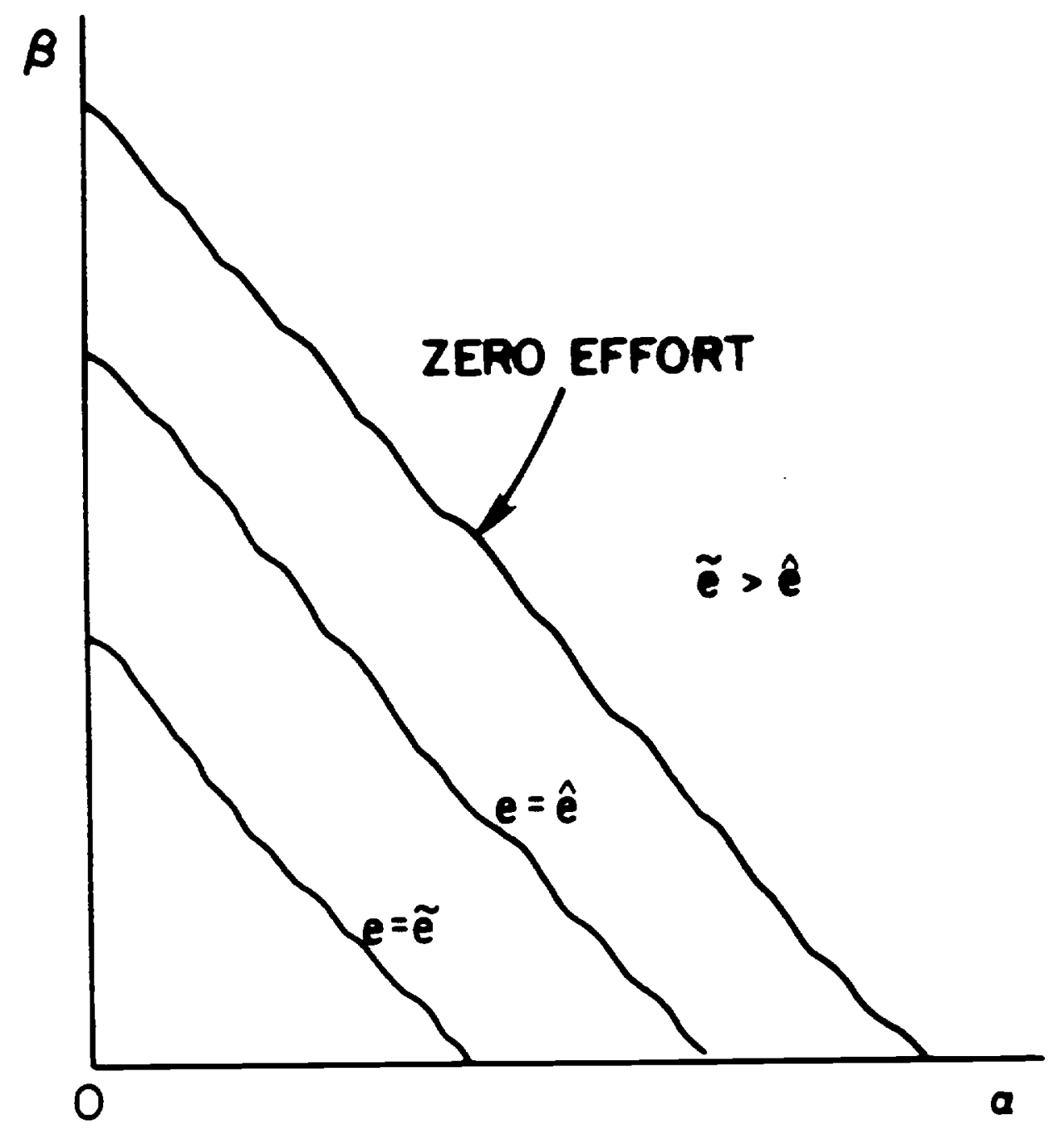

Eigure 3: Constant effort loci with a separable utility function. 


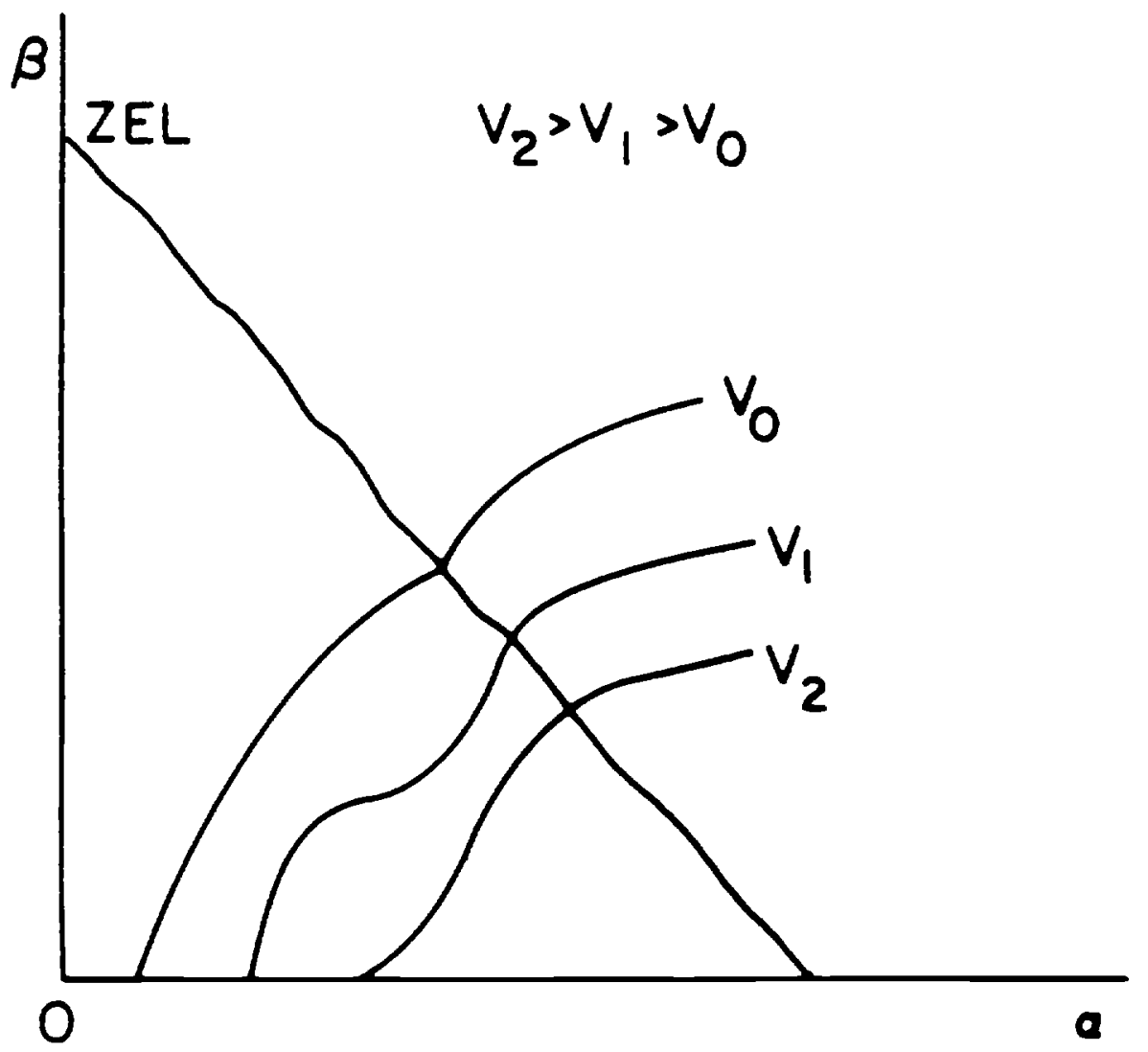

Figure 4 : Samele indiference curves. Separable utility. continuum of effort levels. 


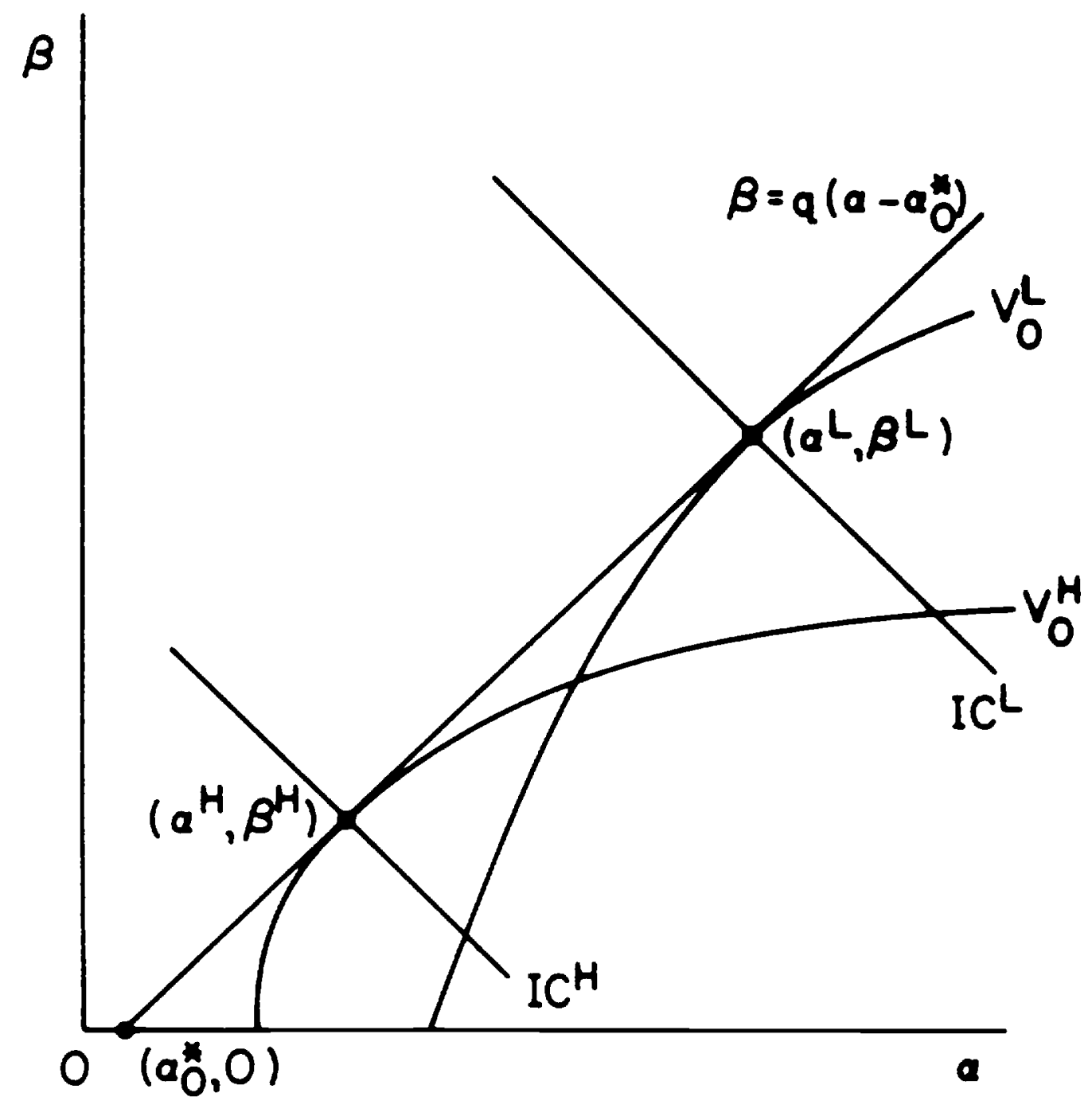

Eigure 3 : Ine tangent to same indifference curve at vio points. 


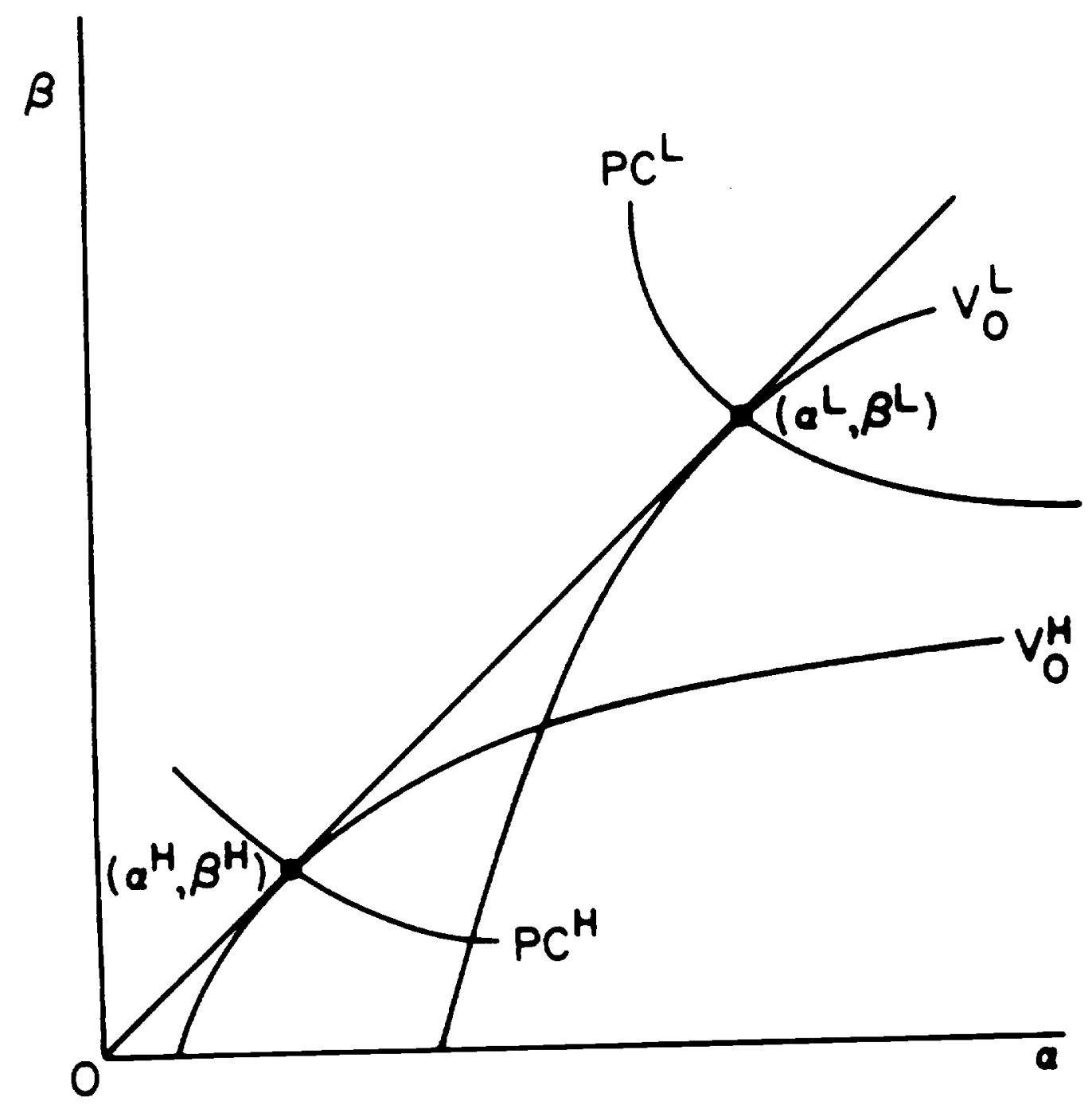

Eigure 6: Ray from origin tangent to same indifierence curve at two points. 


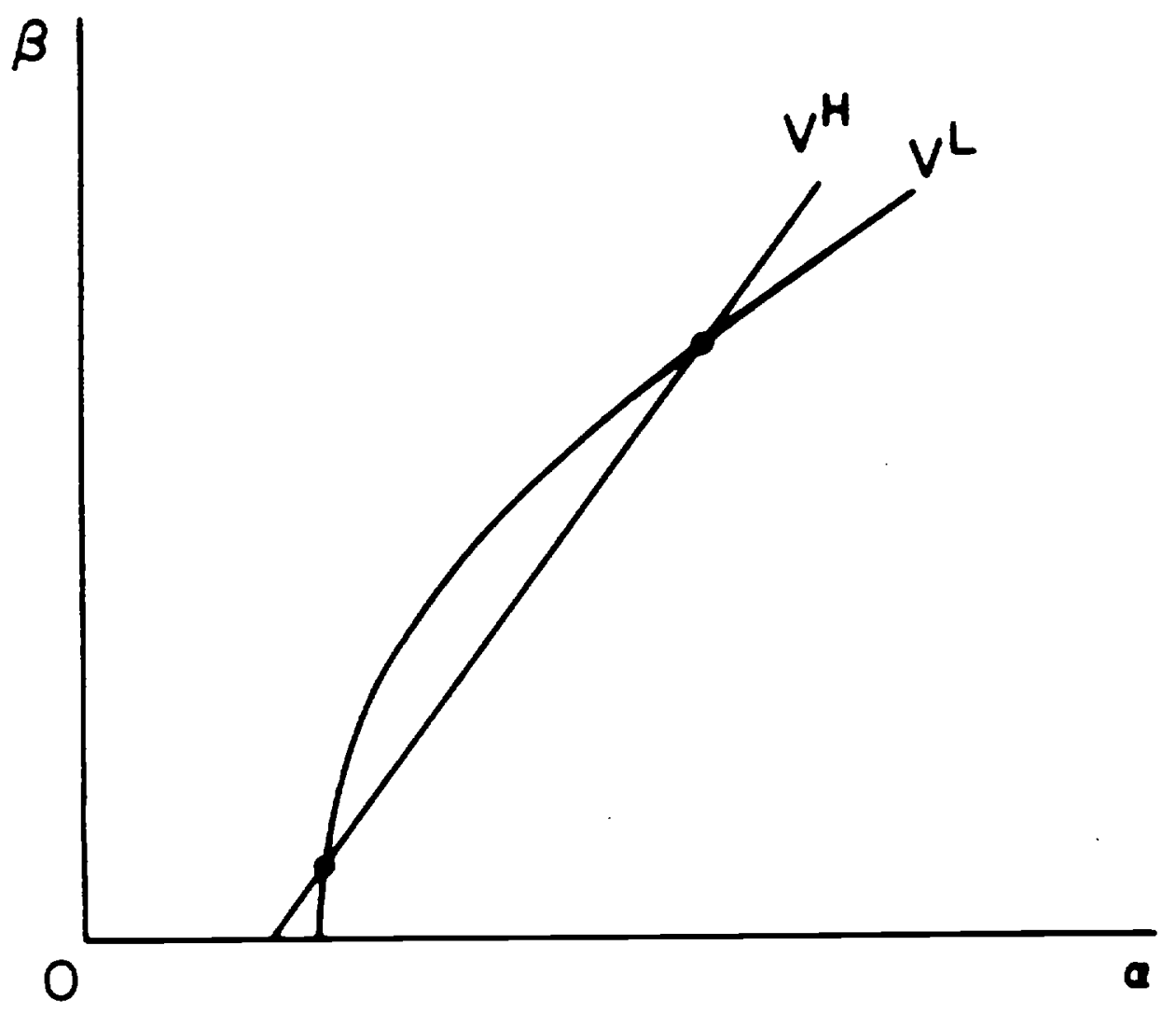

Eigure 7: Without separability, effort may not be monotonic in irsurance provided. 


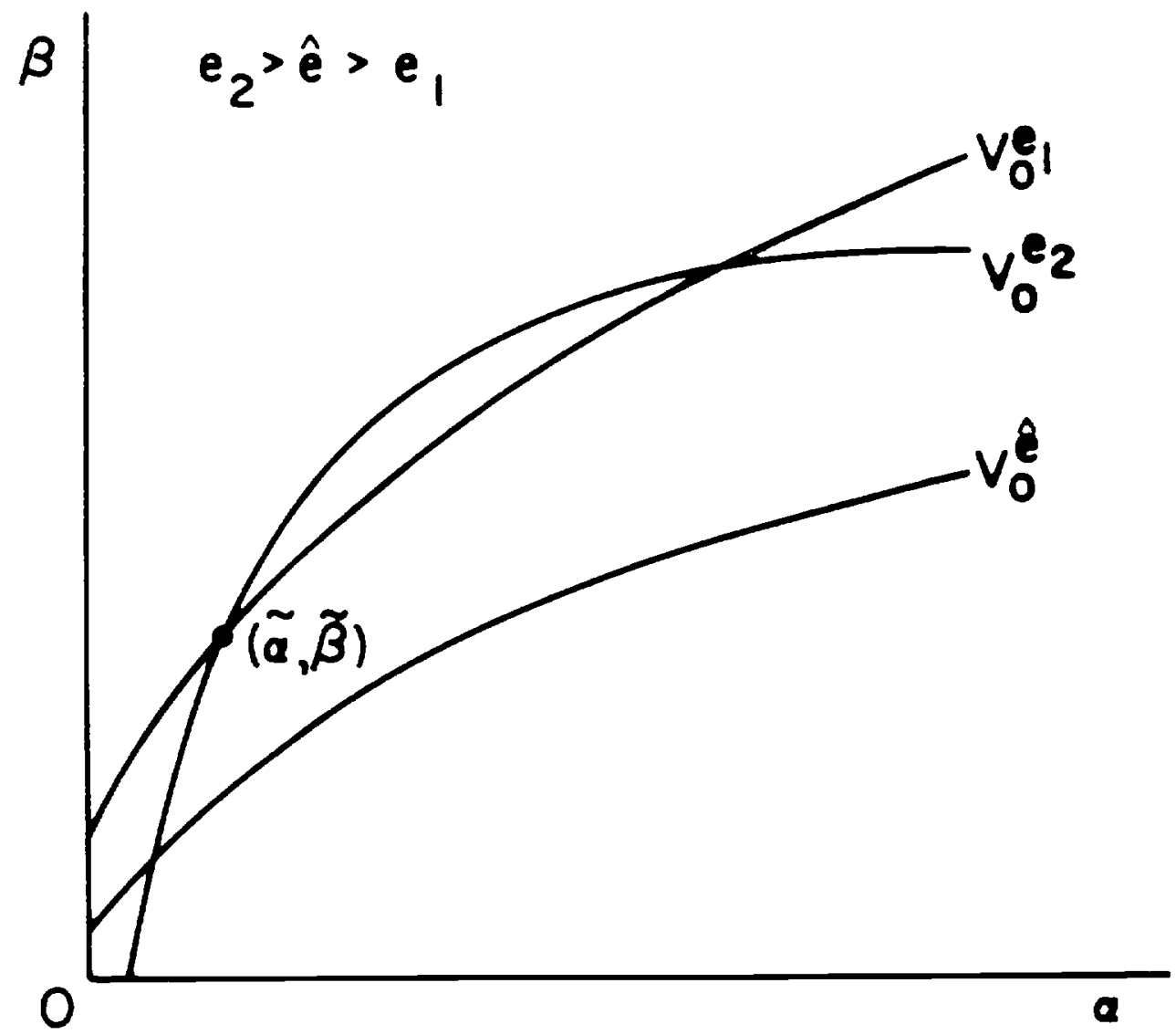

zure 3: With non-separabl- utility and a continuum of efeort levels, some effort levels may be dominated ard effort may rot be continuous. 


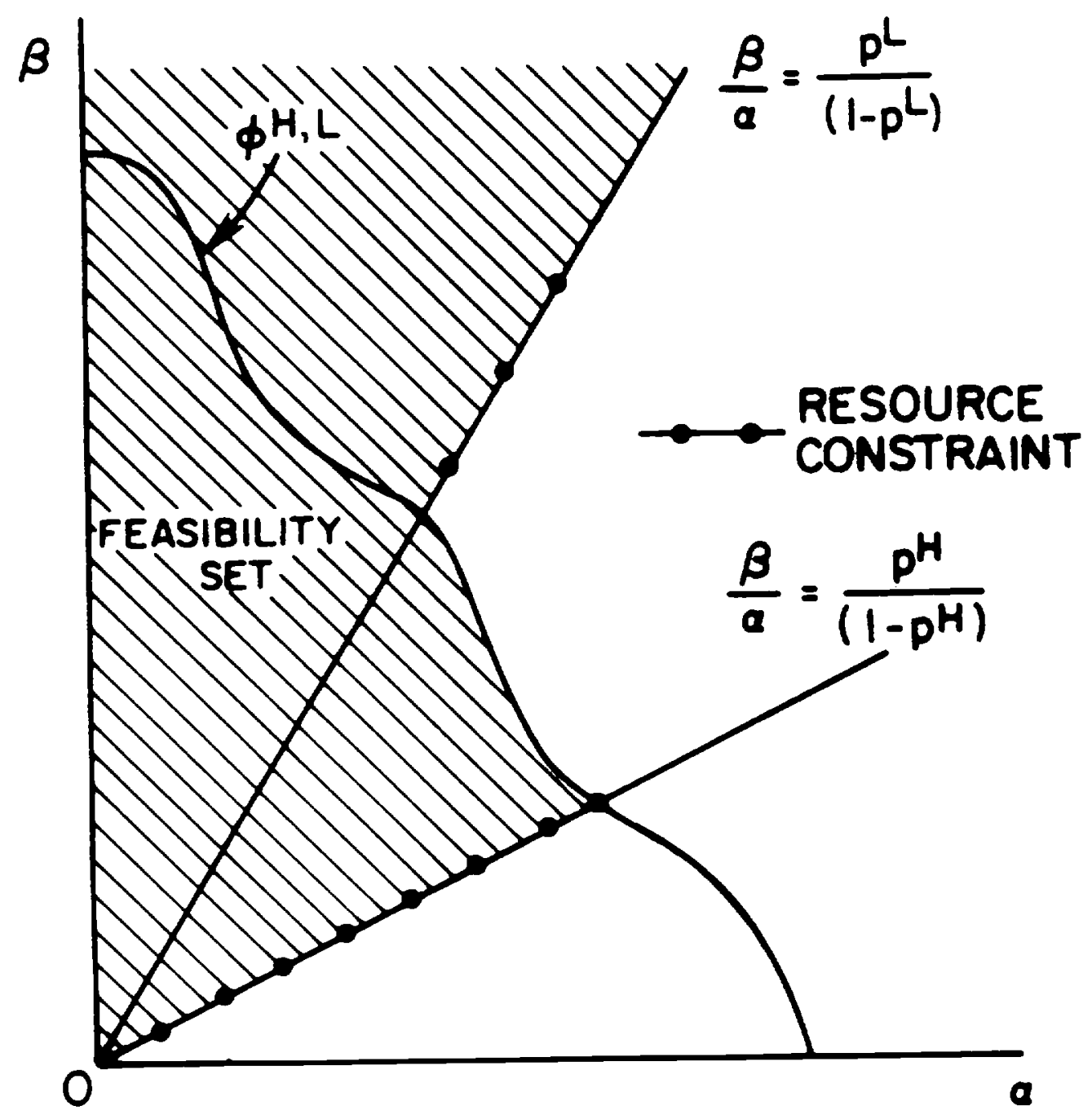

Figure 9: The resource constraint and the feasibility set, two activities, separable utility. 


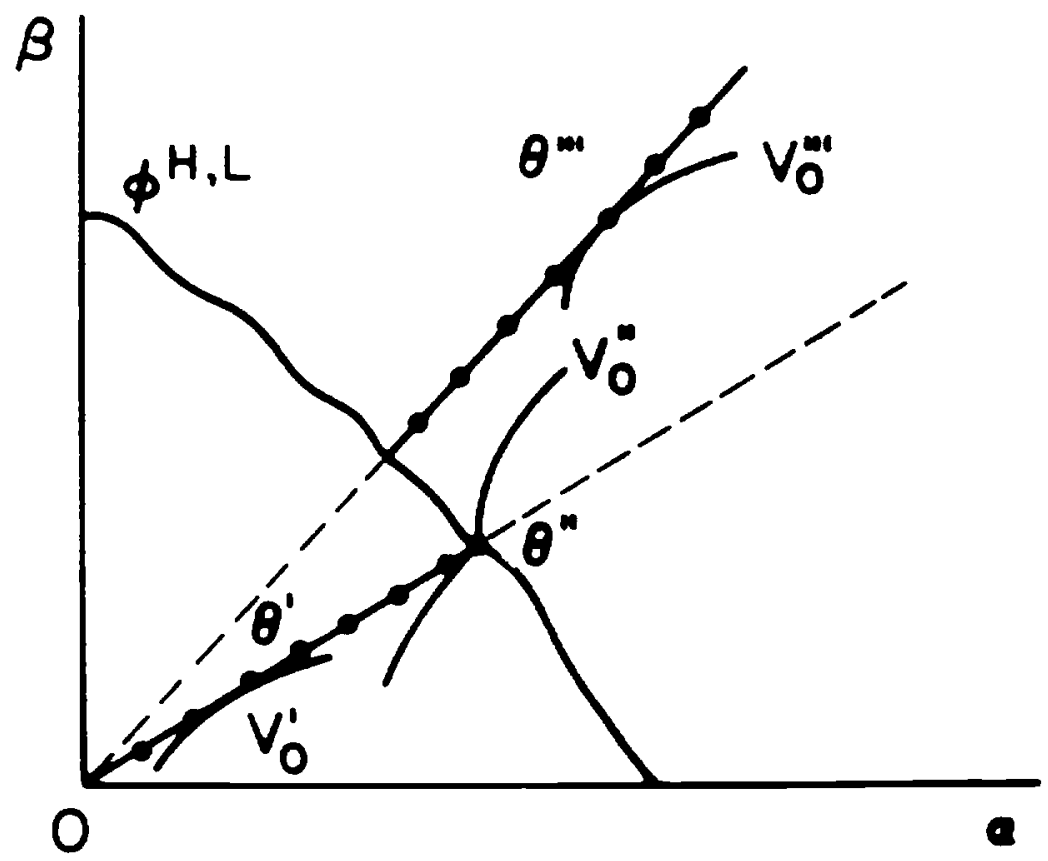

Eigure 10: Possible exclusive contract equilibria, two activities, separable utility. 


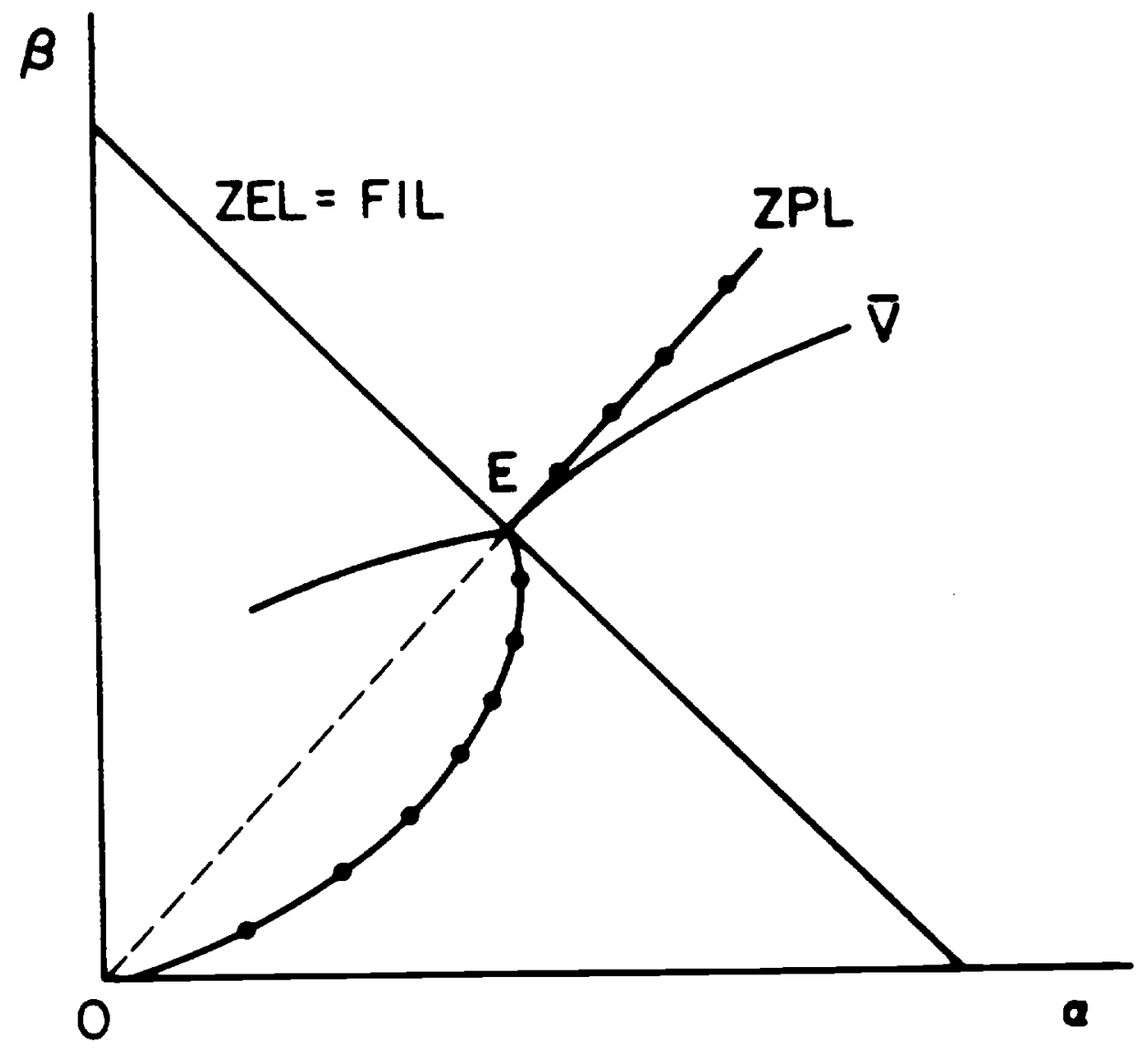

Figure 11: Possible non-existence of a zero profit price equilibrium. 


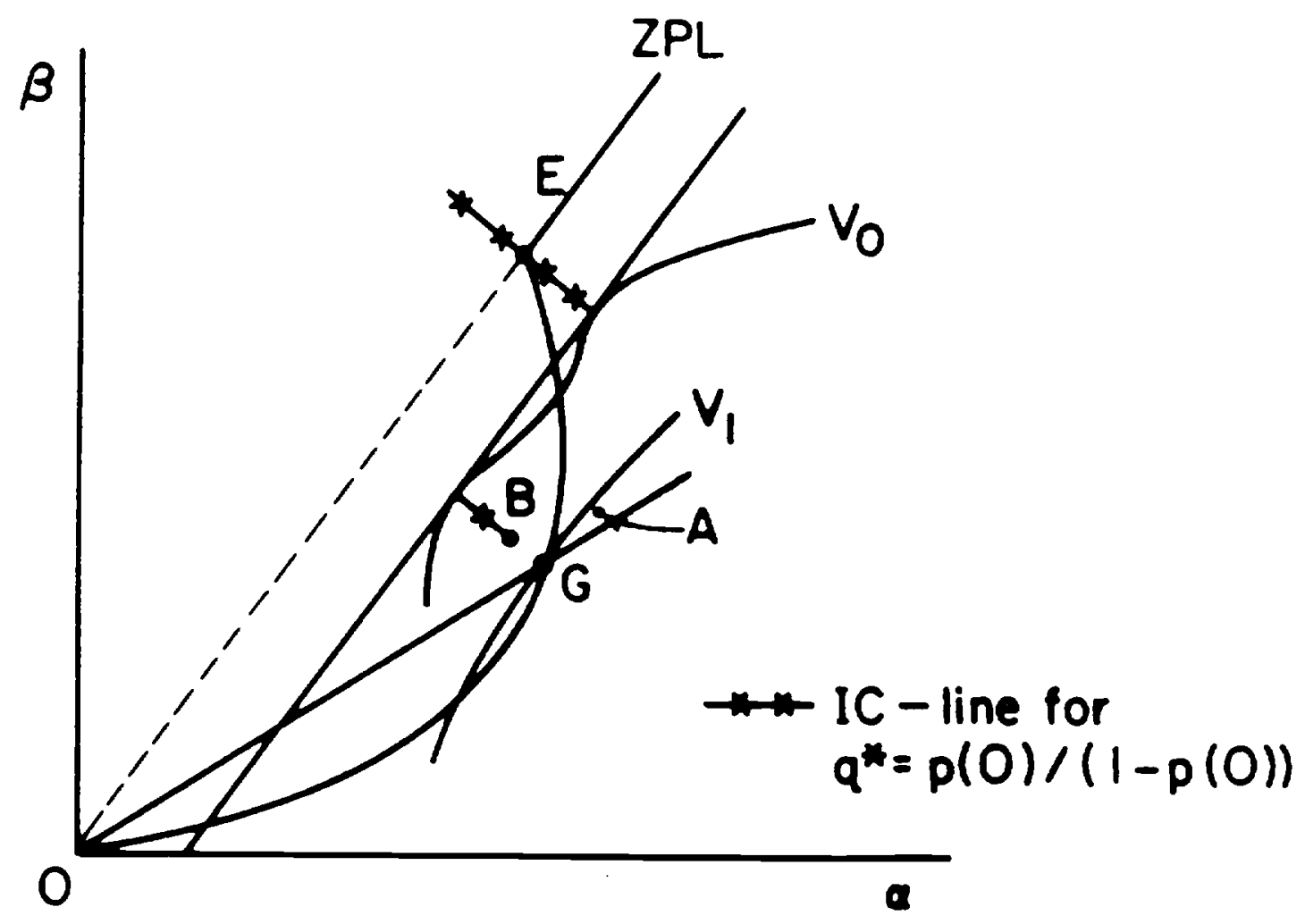

Figure 12: $G$ is uoset by the supplementary contract GA.
$E$ is upset by $B$. 


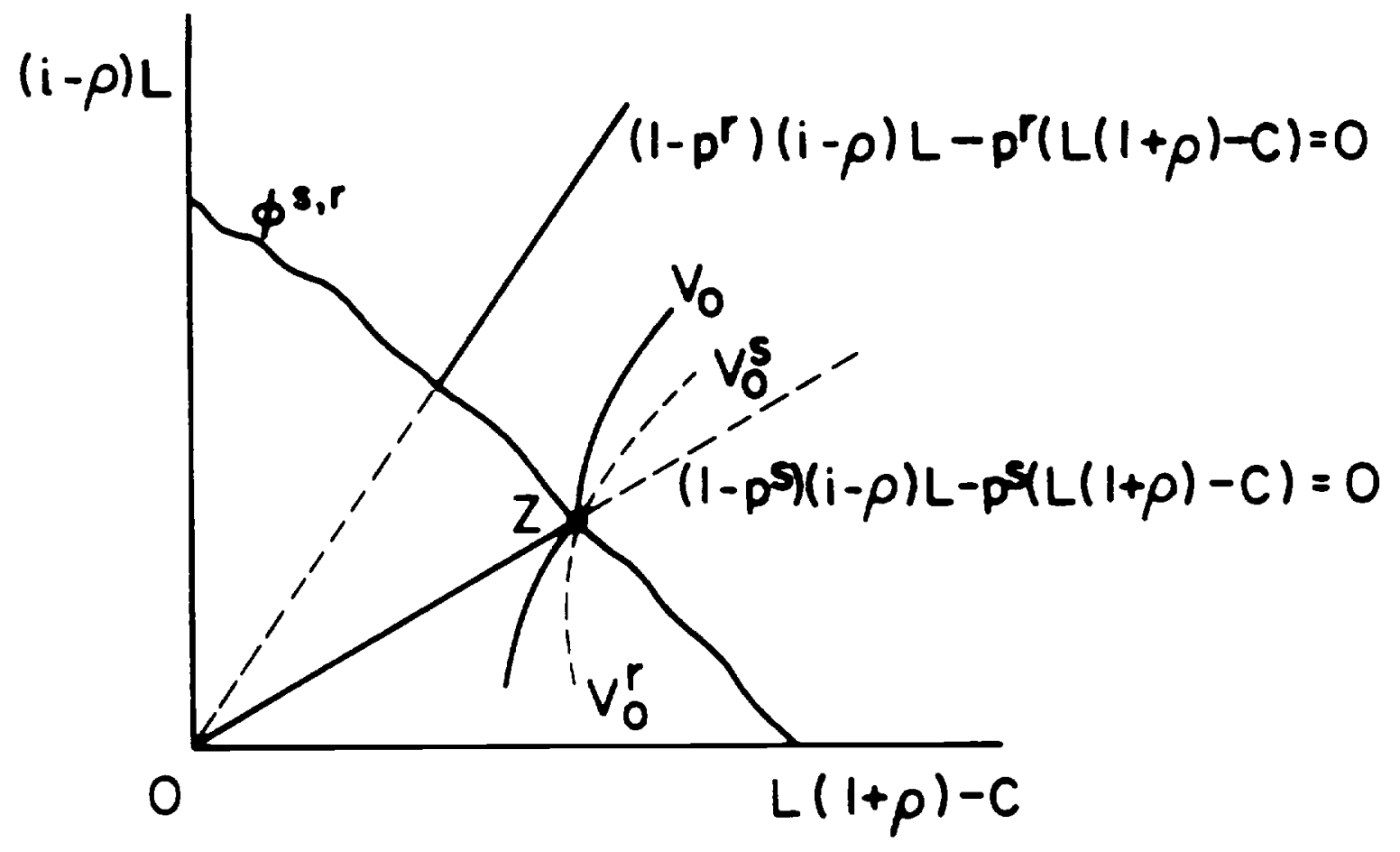

Figure 13: Credit rationing with moral hazard when
the lender cannot observe the riskiness
of the roject chosen by the borrower. 